Alma Mater Studiorum - Università di Bologna DEPARTMENT OF ECONOMICS

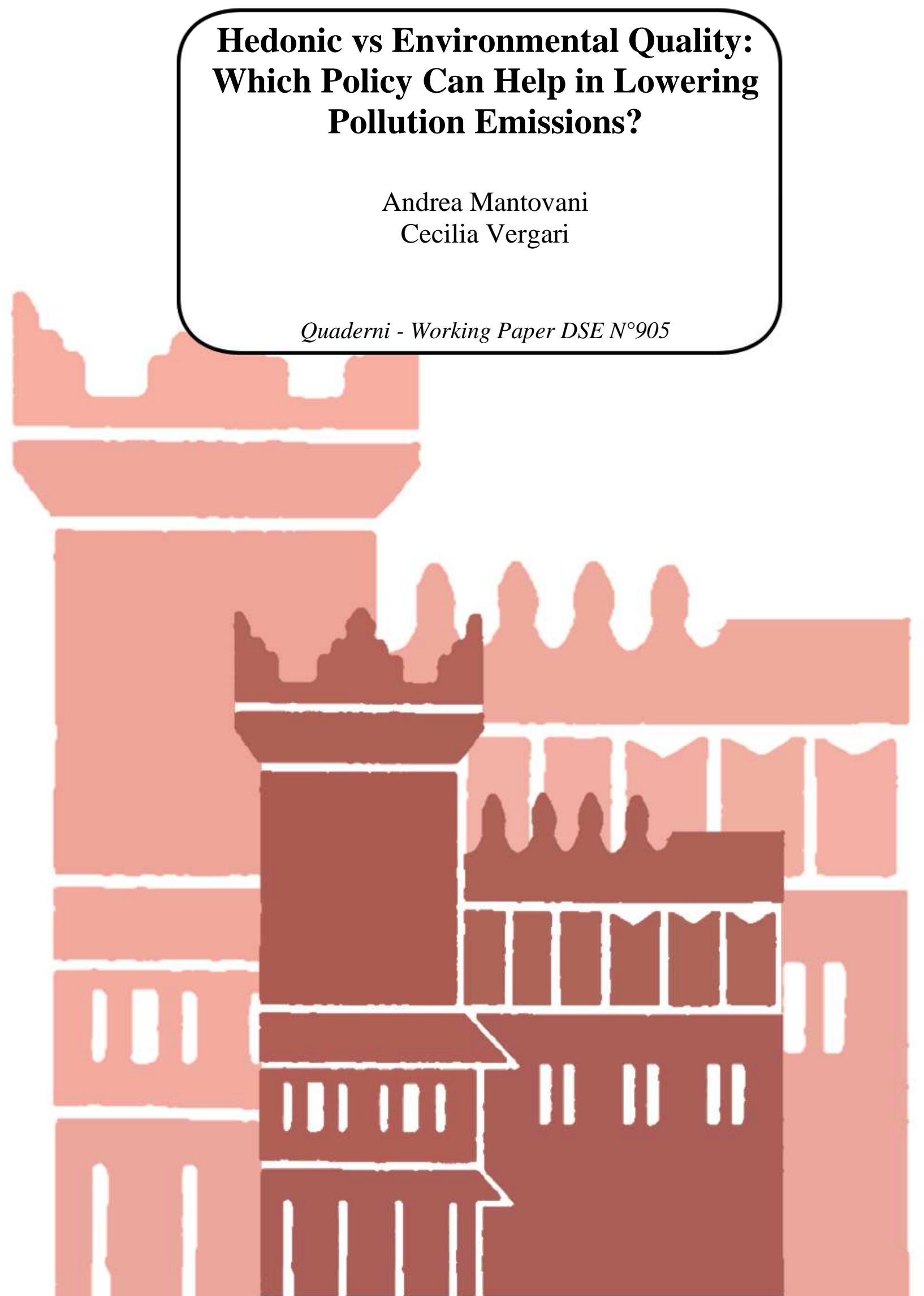




\title{
Hedonic vs Environmental Quality: Which Policy Can Help in Lowering Pollution Emissions?*
}

\author{
Andrea Mantovani ${ }^{\dagger}$ Cecilia Vergari ${ }^{\ddagger}$
}

October 3, 2013

\begin{abstract}
In this paper we compare two policy instruments that can be adopted to curb carbon emissions. The first is a conventional pollution tax. The second is an environmental campaign aiming to influence consumers to switch to a green good. We consider two different scenarios. When consumers are characterized by hedonic quality preferences, in this case the pollution tax is more efficient than the campaign. On the contrary, when consumers develop environmental quality preferences, there are cases in which the campaign is preferred. To sum up, while both policy instruments are effective in reducing pollution emissions, their efficiency viewed from a welfare perspective crucially depends on consumers' environmental awareness.
\end{abstract}

Keywords: Hedonic quality, environmental quality, pollution tax, relative preferences.

JEL Classification: D62, L13; H13.

\footnotetext{
${ }^{*}$ We are grateful to Oscar Amerighi, Luca Lambertini, Willi Semmler, Anastasios Xepapadeas, and the audience at ERMES (Université Pantheon Assas, Paris II) and IIASA for precious comments and discussion. We also thank Lucy Scioscia for professional editing. The usual disclaimer applies.

${ }^{\dagger}$ Department of Economics, University of Bologna, Strada Maggiore 45, 40125 Bologna, Italy, and Barcelona Institute of Economics (IEB), C/ Tinent Coronel Valenzuela 1-11, 08034 Barcelona, Spain; email: a.mantovani@unibo.it.

${ }^{\ddagger}$ Department of Economics, University of Bologna, Strada Maggiore 45, 40125 Bologna, Italy, email: cecilia.vergari@unibo.it
} 


\section{Introduction}

Environmental protection is one of the most important issues on the agenda for policy-makers and governments across the globe. In particular, the debate has focused on which tool should be adopted to convince firms to reduce the level of polluting emissions. The conventional instrument, a tax proportional to level of pollution, has been often criticized, on the ground that it is very difficult to measure the exact damage produced by each firm. Likewise, other alternative tools have been proposed, and policies have been suggested. In the European Union, the creation of a market for the exchange of polluting permits has been considered as an efficient solution, but it relies on the fact that a certain level of pollution is not only accepted, but also supported.

Many commentators claim that educating citizens/consumers to respect the environment may prove to be a very effective instrument, as it rewards green firms to the detriment of brown firms. A recent example of informative policies in the $\mathrm{EU}$ includes the Italian guidelines on $\mathrm{CO}_{2}$ emission savings. ${ }^{1}$ The document ranks vehicles according to their environmental impact. In the US, a similar initiative, the EPA Smart Way program, compares environmental performance of vehicles. ${ }^{2}$ The main question is therefore: how do consumers react to such initiatives? Are they really willing to switch to a green good, even if the pure satisfaction from its consumption is lower than that of a brown good? Electric cars, for example, still have not reached a level of performance comparable to that of traditional combustible vehicles. Depending on whether consumers value the intrinsic quality of the engine more than its environmental impact, such a policy may have a different impact on influencing consumers' choice. This is what we want to capture in our paper.

We adopt a model of vertical differentiation where two firms compete by setting prices. As usual, firms differentiate their products in quality as a way to mitigate competition and increase profits (Gabszewicz and Thisse, 1979; Shaked and Sutton, 1982). However, in our paper one of the two firms produces the green good and pays an additional cost for it. The other produces a polluting good, and may be subject to environmental taxation.

Following our preliminary discussion, we consider two different scenarios, depending on whether consumers perceive the quality of the product as being dependant on the pure performance (hedonic quality) or on the emission of pollution (environmental quality). In the first case, the high quality good is the one that pollutes, while in the second case the opposite holds. This will have a significant impact on the fundamental assumptions on which the theoretical model is based.

In each scenario, we build a two-stage game where the government intervenes in the first stage by either taxing the polluting firm, or by indirectly rewarding the green firm through an environmental campaign. In the second stage, firms compete by setting prices. A crucial point of our model is that the campaign is designed in order to stigmatize pollution. In particular, its final aim is to persuade consumers to attach a positive value to the green good, therefore directing consumers'

\footnotetext{
${ }^{1}$ The Italian guidelines are a joint effort between the Ministry of Transportation, the Ministry of Economic Development and the Ministry of Environment. For further details visit www.mit.gov.it/mit/site.php? $\mathrm{p}=\mathrm{cm} \& \mathrm{o}=\mathrm{vd} \& \mathrm{id}=2724$.

${ }^{2}$ Visit www.epa.gov/smartway/basic-info/index.htm for further details.
} 
preferences towards that good. The main implication is an increase of its demand at the expense of the consumption of the brown good. This is captured by resorting to the theory of relative preferences, recently developed by Ghazzai (2008) and Alexopoulos and Sapp (2006), inter alii. ${ }^{3}$

Our main results are as follows. When consumer preferences favour hedonic quality, taxation prevails as the best policy instrument to achieve the highest level of social welfare. The environmental campaign is too costly, and it only indirectly affects firms' profits. However, consumer surplus shrinks, as taxation reduces total output. On the contrary, when consumers value the environmental quality of the good, then an environmental campaign may be more efficient than the pollution tax, provided that its cost is not excessive, and that the green expansive effect generated by the campaign is sufficiently high. As we will explain in the paper, such an effect positively depends on the average willingness to pay for the environmental quality. However, if the campaign exceeds a certain level of cost, then taxation is preferred. We will also highlight the ambiguous role of the environmental emission parameter: a relatively high emission level can favour the adoption of the campaign if its cost is contained, otherwise the opposite may occur.

The main message of our contribution can therefore be summarized as follows. An environmental campaign based on relative preferences is less efficient than a traditional taxation instrument, as long as consumers are environmentally unconcerned. Things change however with green consumerism, in which case the environmental campaign can be welfare improving with respect to environmental taxation. Our model can thus provide valuable environmental policy indications, depending on region-specific consumers preferences.

As recent studies have shown, environmental concern varies across countries as well as over time due to socio-economic conditions. Kahn and Kotchen (2010) point out that in the last few years the US has experienced substantial erosion in public concern about environmental issues because of the chilling effect of recession. Based on national surveys, they have found a correlation between the unemployment rate and the relevance of global warming. Another example is provided by an European survey conducted between April and May 2011 on citizens' attitude towards the environment (Special Eurobarometer 365). ${ }^{4}$ The result showed that most EU citizens feel that protecting the environment is important to them and that environmental problems have a direct impact on their everyday lives. Moreover, they are inclined also to play a part in protecting the environment and they consider that actions to protect the environment should be carried out at a European level. These two studies suggest therefore that different levels of environmental concern may depend on socio-economic conditions as well as government engagement.

\section{Literature review}

Our paper is related to the literature on optimal tax policy with environmental quality. Among

\footnotetext{
${ }^{3}$ Since the seminal work of Leibenstein (1950), economists have aknowledged the importance of social factors in consumption decisions. Akerlof (1997) has showed that consumer satisfaction increases in proportion to the difference between social classes.

${ }^{4}$ For more details, visit: http://ec.europa.eu/environment/pdf/EB_summary_EB752.pdf
} 
others, Moraga-Gonzales and Padron-Fumero (2002), Lombardini-Riipinen (2005) and Deltas et al. (2013) study how green consumerism may affect the supply of environmental quality in a differentiated duopoly. In particular, Moraga-Gonzalez and Padron-Fumero (2002) compare some frequently used environmental policies: emissions standard, ad valorem tax and technology subsidization. Lombardini-Riipinen (2005) analyses the combination of a uniform ad valorem tax and an emission tax (or a subsidy to consumers buying green products). While these two papers consider a model of vertical differentiation, Deltas et al. (2013) develop a duopoly where products differ both vertically (in terms of their "greenness") and horizontally (e.g., design, style, brand, and convenience). They examine the choice of greenness and the implications of various policy interventions: a tax on a polluting attribute of the products, a cost-sharing of development costs for improving the greenness of a firm's product and a minimum quality standard. By introducing an alternative instrument like the campaign, our paper broadens the scope for government intervention. In a recent book, Lambertini (2013, Ch. 6) provides a careful discussion about the possibility that environmentally aware consumers may regulate firm's behaviour even in absence of an explicit policy measure. We complement this stream of research by endogenizing a policy intervention which makes consumers aware of the damage.

The idea of an environmental campaign as an alternative policy instrument has been recently analyzed in other contributions. Our framework is somewhat similar to Ben Elhadj et al. (2013), in particular with respect to the idea of an environmental policy that affects consumers' preferences. In a vertically differentiated model, they show that the presence of relative preferences for environmental quality reduces pollution damage as it induces the polluting firm to increase its environmental quality. Namely, they analyze how quality competition is affected in the presence of relative preferences for environmental quality and provide a first suggestion for the use of new environmental policy tools. While we do not analyze quality competition, we depart from Ben Elhadj et al. (2013) in what our aim is the comparison of different environmental policies and how the desirability of such policies may depend on the degree of consumers' environmental concern (hedonic vs. environmental qualities). Sartzetakis et al. (2012) analyze the role of information provision about good's environmental damages as a policy instrument that supplements environmental taxation. They consider a dynamic framework and show that as the accumulated stock of information increases, the optimal tax rate declines over time. The information campaign in their model is always an efficient complementary policy because it reduces the asymmetry of information between consumers and manufacturers. Mittnik et al. (2013) develop a growth model and point out how, for long term results, climate policies should encourage and implement structural change of the economy changing the demand structure. They claim that preferences shape the final demand and hence the $\mathrm{CO}_{2}$ emissions of the economy. These papers thus support environmental campaign as a policy instrument to supplement and/or substitute traditional environmental policies. In our paper, we contribute by assessing the efficiency of such policies depending on consumers' environmental concern.

Last but not least, our theoretical conclusions are somewhat in line with Garcia-Gallego and 
Georgantzis (2009). Here the authors consider a vertically differentiated duopoly with heterogenous consumers where the quality choice of the firms captures simultaneously their degree of corporate social responsibility and their environmental quality. They study the effects of an increase in consumers' willingness to pay, which represents a higher social consciousness on the market equilibrium. Their main result is that shifting towards socially responsible consumer preferences is in most cases welfareimproving. However, it can be welfare-reducing when such an increase changes the market structure. Hence, they obtain ambiguous conclusions about the efficiency of environmental campaigns.

The rest of the paper is organized as follows. The next section presents the case with hedonic qualities, while Section 3 deals with environmental qualities. Section 4 summarizes our main results and discusses the assumptions of our model. Section 5 provides our concluding remarks.

\section{Hedonic qualities}

Consider two goods of different qualities: good $H$ produced by firm $H$ is the high quality good, while good $L$ produced by firm $L$ is the low quality good. These goods are vertically differentiated in the traditional sense. Consumers agree that good $H$ has a higher intrinsic quality than good $L$. According to the definition of vertical differentiation, they would all buy good $H$ if they were sold at the same price. We assume that there is a continuum of consumers indexed by $\theta$ which is uniformly distributed in the interval $[0, b]$. Thus, $\theta$ measures consumers' valuation of quality. Parameter $b>0$ measures consumers' heterogeneity as well as the average valuation of the hedonic quality in the market. Each consumer can buy either one unit of good $H$ or one unit of good $L$ or not buy anything at all.

In this initial scenario consumers are environmentally unconcerned. The high quality good has a higher performance than the low quality good but it emits pollution. It represents therefore the brown good. The low quality good is emission-free and it is therefore considered as a green good. Pollution creates an environmental damage $D$ that reduces social welfare. Such a damage is proportional to the emission released by the brown firm: $D=e \cdot x_{H}$, where $x_{H}$ is the quantity produced by firm $H$. Parameter $e>0$ captures the marginal social cost associated to pollution. The government has two alternative policy instruments at its disposal: either a tax $t$ proportional to the polluting emission, or a campaign designed to raise environmental awareness.

We develop the following two-stage game: first, the policy maker decides whether to intervene and which policy instrument to use to reduce the environmental damage for any given level of the per-unit emissions; second, firms compete in prices. We solve the game by backward induction. More precisely, in the following, we solve the price competition stage for the two cases (taxation and campaign) and then make the proper comparison to solve the policy maker decision. 


\subsection{Taxing the polluting good}

Consumer of type $\theta \in[0, b]$ has the following utility:

$$
U(\theta)=\left\{\begin{array}{c}
\theta q_{H}-p_{H}, \text { if she buys the high quality good } \\
\theta q_{L}-p_{L}, \text { if she buys the low quality good, } \\
0, \text { if she refrains from buying. }
\end{array}\right.
$$

The hedonic qualities of the two goods are indicated by $q_{H}>q_{L} ; p_{H}$ and $p_{L}$ denotes the prices of the high and the low quality goods, respectively. Parameter $\theta$ measures the consumer's willingness to pay for hedonic quality. Notice that the above utility function does not account for the presence of pollution. As usual, the consumer who is indifferent between buying the low quality good and not buying at all is:

$$
\theta_{L}=\frac{p_{L}}{q_{L}}
$$

The consumer who is indifferent between buying the low quality good and the high quality good is instead:

$$
\theta_{H}=\frac{p_{H}-p_{L}}{q_{H}-q_{L}}
$$

Demands are then given by $x_{L}=\theta_{H}-\theta_{L}$ and $x_{H}=b-\theta_{H} \cdot{ }^{5}$ As for the cost specification, we assume that producing the green good requires a constant marginal cost $c>0$, whereas the brown quality is produced at zero cost. Nonetheless, the polluting good is subject to a per-unit tax $t$. Thus, $t$ can be interpreted as the tax differential between the two firms, while $c$ represents the marginal production cost differential. ${ }^{6}$ Profit functions are therefore given by:

$$
\begin{aligned}
\pi_{L} & =\left(p_{L}-c\right) x_{L}, \\
\pi_{H} & =\left(p_{H}-t\right) x_{H} .
\end{aligned}
$$

Proceeding by backward induction, we solve the price competition stage and derive the main results, which are valid for each quality configuration. ${ }^{7}$ Using F.O.C.s, equilibrium prices as a function of qualities are:

$$
\begin{aligned}
p_{L}^{*} & =\frac{q_{L} b\left(q_{H}-q_{L}\right)+t q_{L}+2 c q_{H}}{4 q_{H}-q_{L}}, \\
p_{H}^{*} & =\frac{q_{H}\left[2 b\left(q_{H}-q_{L}\right)+2 t+c\right]}{4 q_{H}-q_{L}} .
\end{aligned}
$$

Let us now define:

$$
\begin{gathered}
b_{\min } \equiv \frac{c\left(2 q_{H}-q_{L}\right)}{q_{L}\left(q_{H}-q_{L}\right)}, \\
t_{\max } \equiv \frac{q_{H}\left[2 b\left(q_{H}-q_{L}\right)+c\right]}{\left(2 q_{H}-q_{L}\right)}
\end{gathered}
$$

\footnotetext{
${ }^{5}$ Note that at equilibrium the market is always uncovered because the consumer of type $\theta=0$ always gets a non-positive utility from buying either good.

${ }^{6}$ One can also interpret the decision to produce the green good as a way to avoid the environmental taxation.

${ }^{7}$ We will not explicitly solve the quality competition stage, as our focus is on comparing a new policy tool like the campaign with the traditional tax instrument.
} 
Lemma 1 Both firms are active in the market iff $b>b_{\min }$ and $t<t_{\max }$.

Proof. See Appendix.

We assume that the conditions reported in Lemma 1 hold throughout the section. They indicate that a sufficiently large consumers' heterogeneity together with a non excessive taxation are required for both firms to coexist in the market. We limit our attention to such a case as we want to reproduce a concrete situation where polluting firms compete in the market with non-polluting ones. Moreover, it is usually in the best interest of the society to have the highest number of firms, and this will be also confirmed by the model.

Equilibrium demands/outputs are:

$$
\begin{aligned}
x_{L}^{*} & =\frac{q_{H}\left[q_{L}\left(t+b q_{H}-b q_{L}\right)-c\left(2 q_{H}-q_{L}\right)\right]}{\left(4 q_{H}-q_{L}\right)\left(q_{H}-q_{L}\right) q_{L}}, \\
x_{H}^{*} & =\frac{q_{H}\left[2 b\left(q_{H}-q_{L}\right)+c\right]-t\left(2 q_{H}-q_{L}\right)}{\left(4 q_{H}-q_{L}\right)\left(q_{H}-q_{L}\right)} .
\end{aligned}
$$

By construction, $\partial x_{H}^{*} / \partial t<0$ and $\partial x_{L}^{*} / \partial t>0$. Moreover, notice that $\partial\left(x_{H}^{*}+x_{L}^{*}\right) / \partial t<0$. Taxation shrinks total output, thus implying that consumer surplus decreases when the government applies such a tool. This trade-off between output provision and environmental protection represents one of the point of interest of our analysis. ${ }^{8}$ Equilibrium profits are given by:

$$
\begin{aligned}
\pi_{L}^{*} & =\frac{q_{L}}{q_{H}}\left(q_{H}-q_{L}\right)\left(x_{L}^{*}\right)^{2} \\
\pi_{H}^{*} & =\left(q_{H}-q_{L}\right)\left(x_{H}^{*}\right)^{2}
\end{aligned}
$$

Social welfare as a function of $t$ writes in a compact form as:

$$
S W^{*}(t)=\pi_{L}^{*}+\pi_{H}^{*}+C S_{L}^{*}+C S_{H}^{*}-e \cdot x_{H}^{*}+t \cdot x_{H}^{*}
$$

The precise expression of $C S_{L}^{*}$ and $C S_{H}^{*}$ are reported in the Appendix (See Proof of Proposition 1). Algebraic calculations reveal that $S W^{*}(t)$ is concave in $t$. We can therefore compute the optimal tax rate which maximizes social welfare:

$$
t^{*}=\frac{e\left(4 q_{H}-q_{L}\right)\left(2 q_{H}-q_{L}\right)-q_{H}\left[b\left(4 q_{H}-3 q_{L}\right)\left(q_{H}-q_{L}\right)+2 c\left(2 q_{H}-q_{L}\right)\right]}{q_{H}\left(4 q_{H}-3 q_{L}\right)}
$$

Taking into account that $t^{*}$ has to be non-negative, and that the conditions appearing in Lemma 1 have to be satisfied:

Lemma $2 t^{*} \in\left[0, t_{\max }\right)$ when $e \in\left[e_{\min }^{t}, e_{\max }^{t}\right)$.

\footnotetext{
${ }^{8}$ Controversies exist between those arguing that environmental policy is likely to stifle competitiveness by imposing additional burdens on firms' production costs, and those claiming that new environmental technologies can prompt competitiveness among firms. Although this is not the specific objective of our analysis, the trade-off that has just been shown is part of such an ongoing discussion.
} 
Proof. From (4), $t^{*} \geqslant 0$ iff $e \geqslant e_{\min }^{t}=\frac{q_{H}\left[b\left(4 q_{H}-3 q_{L}\right)\left(q_{H}-q_{L}\right)+2 c\left(2 q_{H}-q_{L}\right)\right]}{\left(4 q_{H}-q_{L}\right)\left(2 q_{H}-q_{L}\right)}$, while $t^{*}<t_{\max }$ iff $e<e_{\max }^{t}=\frac{q_{H}\left[b\left(4 q_{H}-3 q_{L}\right)\left(q_{H}-q_{L}\right)+c\left(3 q_{H}-2 q_{L}\right)\right]}{\left(2 q_{H}-q_{L}\right)^{2}}$.

For very low values of $e$, the optimal tax is zero because the negative effect on output is higher than the positive effect induced by the reduction in the emission level. ${ }^{9}$ On the contrary, for very high values of the polluting emission, the optimal tax is $t_{\max }$. In such a case, the profit of the high quality firm tends to zero. It is relatively easy to demonstrate that the government would prefer to leave an $\varepsilon \rightarrow 0$ to the polluting firm, and then still have a duopoly, instead of pushing it out from the market. The previous discussion is summarized into:

Remark 1 Depending on the value associated to the environmental damage $e$, the government optimally sets: (i) $t=0$ when $e<e_{\min }^{t}$; (ii) $t=t^{*}$ when $e \in\left[e_{\min }^{t}, e_{\max }^{t}\right.$ ); (iii) $t=t_{\max }$ when $e \geqslant e_{\max }^{t}$

Depending on the emission level, we find therefore three different values of $t$ which should be inserted in the social welfare function (3). These equilibrium values, as well as those associated to the optimal environmental campaign, are reported in the Appendix (see again the Proof of Proposition $1)$.

\subsection{Supporting the environmental campaign}

Assume that the policy maker implements a campaign to inform consumers about the damaging emission released by good $H$. As introduced before, the campaign that we have in mind aims at creating a social stigma against the consumption of the polluting (brown) good. This should encourage consumers to increase the consumption of the green good at the expense of the brown one. This generates a green expansive effect, as it will be labelled in the paper.

Formally, a new term appears in the indirect utility, namely $\gamma>0$, which multiplies the quality gap: ${ }^{10}$

$$
U(\theta)=\left\{\begin{array}{c}
\theta q_{H}-p_{H}-\gamma\left(q_{H}-q_{L}\right), \text { if she buys the high quality good, } \\
\theta q_{L}-p_{L}+\gamma\left(q_{H}-q_{L}\right), \text { if she buys the low quality good, } \\
0, \text { if she refrains from buying. }
\end{array}\right.
$$

The consumer indifferent between buying the low quality good and not buying at all is:

$$
\theta_{L}=\gamma+\frac{p_{L}-\gamma q_{H}}{q_{L}}=\frac{p_{L}-\gamma\left(q_{H}-q_{L}\right)}{q_{L}}
$$

\footnotetext{
${ }^{9}$ Although mathematically correct, we disregard the case in which the government offers a subsidy (negative $t$ ) to help the polluting firm.

${ }^{10}$ An alternative, and probably more costly campaign should inform consumers about the emission level. This could be represented by:

$$
\begin{aligned}
& \theta q_{H}-p_{H}-\gamma e \\
& \theta q_{L}-p_{L}+\gamma e .
\end{aligned}
$$

Notice that in such a scenario $\gamma$ represents the level of accuracy of the information provided. One can think of $\gamma \in(0,1)$ as a measure of such accuracy. However, such a formulation increases the difficulty of the mathematical expressions without changing the main message.
} 
The consumer indifferent between buying the low quality good and the high quality good is:

$$
\theta_{H}=2 \gamma+\frac{p_{H}-p_{L}}{q_{H}-q_{L}}=\frac{p_{H}-p_{L}+2 \gamma\left(q_{H}-q_{L}\right)}{q_{H}-q_{L}}
$$

Note that, given prices, the market share of $L$ increases in $\gamma$. The consumer that is indifferent between not buying at all and buying the low quality $\left(\theta_{L}\right)$ moves to the left, while the one indifferent between buying the low quality and the high quality $\left(\theta_{H}\right)$ moves to the right. Contrary to the previous case, the market (hypothetically) can be covered. Consumer of type $\theta=0$ can have a positive utility from buying $L$ if $\gamma\left(q_{H}-q_{L}\right)>p_{L}$. However, we can show that this is not compatible with the basic assumptions of the model, in particular that $p_{H}>p_{L} .{ }^{11}$ We focus therefore on the uncovered market situation.

Demands are formally written as before: $x_{L}=\theta_{H}-\theta_{L}$ and $x_{H}=b-\theta_{H}$, yet the indifferent consumers are affected by $\gamma$, as represented in (6) and (5). Producing the low quality (green) good still requires a per-unit cost $c>0$, while the high quality (brown) is produced at zero cost. Profit functions are expressed as:

$$
\begin{aligned}
\pi_{H} & =x_{H} \cdot p_{H}, \\
\pi_{L} & =\left(p_{L}-c\right) x_{L} .
\end{aligned}
$$

As there is no per-unit tax levied on the brown good, pollution is indirectly fought through the effect of the campaign on consumers' preferences. Equilibrium prices can easily be obtained:

$$
\begin{aligned}
p_{L}^{* *} & =\frac{2 c q_{H}+\left(q_{H}-q_{L}\right)\left(2 \gamma q_{H}+b q_{L}\right)}{4 q_{H}-q_{L}}, \\
p_{H}^{* *} & =\frac{c q_{H}+\left(q_{H}-q_{L}\right)\left[2 b q_{H}-\gamma\left(3 q_{H}-q_{L}\right)\right]}{4 q_{H}-q_{L}} .
\end{aligned}
$$

The following condition is compatible with the basic assumptions of the model:

Lemma 3 Provided $b>b_{\min }$, both firms stay in the market iff $b>b_{\min }$ and $\gamma<\min \left\{\frac{b\left(2 q_{H}-q_{L}\right)\left(q_{H}-q_{L}\right)-c q_{H}}{\left(5 q_{H}-q_{L}\right)\left(q_{H}-q_{L}\right)}, \frac{2 c q_{H}+b\left(q_{H}-q_{L}\right) q_{L}}{\left(2 q_{H}-q_{L}\right)\left(q_{H}-q_{L}\right)}\right\} \equiv \gamma_{\max }$.

Proof. See the Appendix.

Equilibrium variables are then:

$$
\begin{aligned}
x_{L}^{* *} & =\frac{q_{H}\left[\left(q_{H}-q_{L}\right)\left(2 \gamma q_{H}-q_{L}\right)-c\left(2 q_{H}-q_{L}\right)\right]}{q_{L}\left(4 q_{H}-q_{L}\right)\left(q_{H}-q_{L}\right)}, x_{H}^{* *}=\frac{p_{H}^{* *}}{\left(q_{H}-q_{L}\right)} ; \\
\pi_{L}^{* *} & =\frac{q_{L}}{q_{H}}\left(q_{H}-q_{L}\right)\left(x_{L}^{*}\right)^{2}, \pi_{H}^{* *}=\frac{\left(x_{H}^{* *}\right)^{2}}{\left(q_{H}-q_{L}\right)} .
\end{aligned}
$$

By construction, we find that $\partial x_{L}^{* *} / \partial \gamma>0$ and $\partial x_{H}^{* *} / \partial \gamma>0<0$, as expected. However, differently from before, total output increases in $\gamma$. Consumer surplus tends therefore to be higher than in the

\footnotetext{
${ }^{11}$ Formally, $\theta_{L}<0$ requires a relatively high value of $\gamma$, and this is not compatible with the condition $p_{H}>p_{L}$, that requires on the contrary a low value of $\gamma$. The market coverage configuration would only arise when the low green quality firm dominates the market. We discuss in Section 4 the consequences of extending the analysis to larger values of the parameter $\gamma$.
} 
previous case, thus solving the trade-off between total output (that determines the degree of market competition) and total emissions (that determines the degree of environmental protection) that we highlighted with the taxation instrument.

The social welfare function writes in a compact way as :

$$
S W^{* *}(\gamma)=\pi_{L}^{* *}+\pi_{H}^{* *}+C S_{L}^{* *}+C S_{H}^{* *}-e \cdot x_{H}^{* *}-s \frac{\gamma^{2}}{2},
$$

where the precise expressions of $C S_{L}^{* *}+C S_{H}^{* *}$ are confined to the Appendix (see Proof of Proposition 1). Differently from the taxation case, the social welfare is concave in the policy instrument only for sufficiently high values of the marginal cost of the campaign. In particular, this requires:

$$
s>\frac{\left(q_{H}-q_{L}\right)\left(12 q_{H}^{3}+19 q_{H}^{2} q_{L}-13 q_{H} q_{L}^{2}+2 q_{L}^{3}\right)}{q_{L}\left(4 q_{H}-q_{L}\right)^{2}} \equiv s_{\text {min }}
$$

We assume that $s>s_{\text {min }}$. This accounts for the fact that it becomes increasingly difficult to convince consumers to buy the green good. We compute the optimal $\gamma$ level which maximizes social welfare:

$$
\gamma^{*}=\frac{q_{H}\left(c q_{H} q_{L}-12 c q_{H}^{2}-3 b q_{L}^{3}+c q_{L}^{2}+11 b q_{H} q_{L}^{2}-8 b q_{H}^{2} q_{L}\right)+e q_{L}\left(q_{L}-4 q_{H}\right)\left(q_{L}-3 q_{H}\right)}{s q_{L}\left(q_{L}-4 q_{H}\right)^{2}-\left(q_{H}-q_{L}\right)\left(12 q_{H}^{3}+2 q_{L}^{3}-13 q_{H} q_{L}^{2}+19 q_{H}^{2} q_{L}\right)} .
$$

Taking into account that $\gamma^{*} \geq 0$ and that the conditions from Lemma 4 have to be satisfied, we find:

Lemma 4 Assume $\gamma_{\max }=\frac{b\left(2 q_{H}-q_{L}\right)\left(q_{H}-q_{L}\right)-c q_{H}}{\left(5 q_{H}-q_{L}\right)\left(q_{H}-q_{L}\right)}$. Then $\gamma^{*} \in\left[0, \gamma_{\max }\right)$ when $e \in\left[e_{\min }^{\gamma}, e_{\max }^{\gamma}\right)$.

Proof. See the Appendix, where one can also find the precise values of $e_{\min }^{\gamma}$ and $e_{\max }^{\gamma}$.

The optimal policy is $\gamma=0$ as long as the emission level is very low because the cost of the campaign does not compensate the positive effect linked to the emission reduction. In contrast, for very high values of the emission, the optimal policy is $\gamma=\gamma_{\max }$. In such a case, the profit of the high quality firm are still positive (note that for $\gamma=\gamma_{\max }$ the demand for the high quality good is still positive). The previous discussion is summarized into:

Remark 2 Depending on the value taken by the polluting emission e, the government optimally sets: (i) $\gamma=0$ when $e<e_{\min }^{\gamma}$; (ii) $\gamma=\gamma^{*}$ when $e \in\left[e_{\min }^{\gamma}, e_{\max }^{\gamma}\right.$ ); (iii) $\gamma=\gamma_{\max }$ when $e \geqslant e_{\max }^{t}$.

\subsection{Comparing the two instruments under hedonic qualities}

We now compare the two policy instruments: taxation versus campaign. First of all, we need to rank the threshold values of $e$ that indicate the regions where different levels of social welfare occur. The ranking depends on the combination between the average hedonic quality $b$ and the cost of the campaign s. In the Appendix we detail all the possible cases and perform the relative comparisons. The following proposition summarizes the most important result:

Proposition 1 Assume that consumers are not environmentally concerned (hedonic preferences). The social welfare preferences are such that, if the cost of the environmental campaign is sufficiently high $\left(s>s_{\text {min }}\right)$, then the tax instrument is always preferred to the environmental campaign. 
Proof. See the Appendix.

When the social welfare associated to the environmental campaign is concave, the government always prefers the taxation instrument. Under the assumptions of our model, taxation can also completely eliminate the high quality firm $H$ (or leave it with zero profit), while the environmental campaign entails a high cost $s$ which makes such an effort undesirable. These social preferences are mainly due the fact that the conditions for the uncovered market that we analyze imply that $\gamma$ cannot be too high. This is to assume that the campaign is not "revolutionary", that is not so effective to induce all consumers (also the more $H$ oriented consumer) to switch to the green good. We believe that such an assumption is realistic as it captures a situation in which at least a part of the population would not change its consumption behaviour after the campaign. ${ }^{12}$

Results change if we consider relatively low costs associated to the environmental campaign. We discuss in Section 4 this issue.

\section{$3 \quad$ Environmental qualities}

We next consider the case in which consumers value the environmental quality. Formally $\theta$ now measures the environmental quality rather then the hedonic quality. We assume that consumers consider as low quality good the one that pollutes (brown good), whereas the high quality good is the green one, which has zero emissions. The environmental damage is then $D=e \cdot x_{L}$. Note that parameter $b>0$, again, measures consumers' heterogeneity but differently from the previous scenario, it now measures the average valuation of the environmental quality in the market. Thus, we can state that the higher is $b$ the more the average consumer cares about the environment.

As before, the government may intervene through a traditional taxation of the polluting good or through a campaign that augments consumers' environmental sensitivity by introducing relative preferences. Accordingly, we develop the following two-stage game that we solve by backward induction: first, the policy maker decides whether to intervene and which policy instrument to use to reduce the environmental damage; second, firms compete in prices.

\subsection{Taxing the polluting good}

Consumer of type $\theta \in[0, b]$ has the following utility:

$$
U(\theta)=\left\{\begin{array}{c}
\theta q_{H}-p_{H}, \text { if she buys the high (green) quality good, } \\
\theta q_{L}-p_{L}, \text { if she buys the low (brown) quality good, } \\
0, \text { if she refrains from buying. }
\end{array}\right.
$$

where $q_{H}>q_{L}$ indicates the environmental qualities of the two goods and thus $\theta$ measures consumers' willingness to pay for environmental quality. The consumer indifferent between buying the brown quality good and not buying at all is:

$$
\theta_{L}=\frac{p_{L}}{q_{L}}
$$

\footnotetext{
${ }^{12}$ We discuss in more details the role of $\gamma$ in Section 4.
} 
The consumer indifferent between buying the brown quality good and the green quality good is:

$$
\theta_{H}=\frac{p_{H}-p_{L}}{q_{H}-q_{L}}
$$

Demands are given again by $x_{L}=\theta_{H}-\theta_{L}$ and $x_{H}=b-\theta_{H}$. As before, producing the green quality good requires a constant marginal cost $c>0$, while the brown quality good is assumed to be produced at zero cost. However, this good is subject to a per-unit tax $t$ which represents the tax differential between the two firms. On the other hand, $c$ represents the marginal production cost differential. Profit functions are therefore:

$$
\begin{aligned}
\pi_{L} & =\left(p_{L}-t\right) x_{L}, \\
\pi_{H} & =\left(p_{H}-c\right) x_{H} .
\end{aligned}
$$

Proceeding by backward induction, we solve the price competition stage and derive the main results, which are valid for each quality configuration. Equilibrium prices are:

$$
\begin{aligned}
p_{H}^{* E} & =\frac{q_{H}\left[2 c+t+2 b\left(q_{H}-q_{L}\right)\right]}{4 q_{H}-q_{L}}>0 \\
p_{L}^{* E} & =\frac{c q_{L}+2 t q_{H}+q_{L} b\left(q_{H}-q_{L}\right)}{4 q_{H}-q_{L}}>0
\end{aligned}
$$

Additional superscript $E$ indicates that we are considering environmental preferences. This will be used throughout this section to differentiate from the hedonic preferences scenario that has been considered in the previous section.

If $p_{H}>p_{L}$, both demands are positive. If instead $p_{H} \leq p_{L}$, the demand for the low quality good is zero: $D_{L}=0$ and $D_{H}=b-\frac{p_{H}}{q_{H}}$. We consider the case in which both firms stay in the market. This requires the conditions provided in the following lemma to hold. Define:

$$
\begin{gathered}
b_{\min }^{E} \equiv \frac{c\left(2 q_{H}-q_{L}\right)}{2 q_{H}\left(q_{H}-q_{L}\right)}, \\
t_{\max }^{E} \equiv \frac{q_{L}\left[c+b\left(q_{H}-q_{L}\right)\right]}{\left(2 q_{H}-q_{L}\right)} .
\end{gathered}
$$

Lemma 5 Both firms stay in the market iff $b>b_{\min }^{E}$ and $t<t_{\max }^{E}$.

Proof. See the Appendix.

Equilibrium demands/outputs are:

$$
\begin{aligned}
x_{L}^{* E} & =\frac{q_{H}\left[c q_{L}-t\left(2 q_{H}-q_{L}\right)+b q_{L}\left(q_{H}-q_{L}\right)\right]}{\left(q_{H}-q_{L}\right)\left(4 q_{H}-q_{L}\right) q_{L}} \\
x_{H}^{* E} & =\frac{2 b q_{H}\left(q_{H}-q_{L}\right)-c\left(2 q_{H}-q_{L}\right)+t q_{H}}{\left(4 q_{H}-q_{L}\right)\left(q_{H}-q_{L}\right)}
\end{aligned}
$$

Following the assumption of environmental qualities, we can observe that $\partial x_{L}^{* E} / \partial t<0$ and $\partial x_{H}^{* E} / \partial t>$ 0 . Moreover, notice that $\partial\left(x_{H}^{* E}+x_{L}^{* E}\right) / \partial t<0$ : total output decreases with $t$. Equilibrium profits 
are given by:

$$
\begin{aligned}
\pi_{L}^{* E} & =\frac{q_{L}}{q_{H}}\left(q_{H}-q_{L}\right)\left(x_{L}^{* E}\right)^{2} \\
\pi_{H}^{* E} & =\left(q_{H}-q_{L}\right)\left(x_{H}^{* E}\right)^{2} .
\end{aligned}
$$

They are expressed in the same way as with hedonic preferences, but obviously with different equilibrium quantities.

Social welfare as a function of $t$ writes in a compact form as:

$$
S W^{* E}(t)=\pi_{L}^{* E}+\pi_{H}^{* E}+C S_{L}^{* E}+C S_{H}^{* E}-e \cdot x_{L}^{* E}+t \cdot x_{L}^{* E},
$$

where the value of $C S_{L}^{* E}+C S_{H}^{* E}$ is reported in the Appendix (see Proof of Proposition 2). Algebraic calculations show that the social welfare function is still concave in $t$. The optimal tax rate can be found as follows:

$$
\frac{\partial S W^{* E}(t)}{\partial t}=0 \Longleftrightarrow t=\frac{e\left(4 q_{H}-q_{L}\right)\left(2 q_{H}-q_{L}\right)+q_{L}\left[b q_{L}\left(q_{H}-q_{L}\right)-2 c\left(2 q_{H}-q_{L}\right)\right]}{q_{H}\left(4 q_{H}-3 q_{L}\right)} \equiv t^{* E} .
$$

Taking into account that $t^{* E}$ has to be non-negative, and that the conditions from Lemma 5 have to be satisfied:

Lemma $6 t^{* E} \in\left[0, t_{\max }^{E}\right)$ when $e \in\left[\max \left\{0, e_{\min }^{t E}\right\}, e_{\max }^{t E}\right)$.

Proof. From (13), $t^{* E} \geq 0$ iff $e \geq e_{\min }^{t E}=\frac{q_{L}\left[2 c\left(2 q_{H}-q_{L}\right)-b q_{L}\left(q_{H}-q_{L}\right)\right]}{\left(4 q_{H}-q_{L}\right)\left(2 q_{H}-q_{L}\right)} \geq 0 \Longleftrightarrow b \leq$ $\frac{2 c\left(2 q_{H}-q_{L}\right)}{q_{L}\left(q_{H}-q_{L}\right)} \equiv \widehat{b} \cdot t^{* E}<t_{\max }^{E}$ iff $e<e_{\max }^{t E}=\frac{c\left(2 q_{H}-q_{L}\right)+2 b\left(q_{H}-q_{L}\right)^{2}}{\left(2 q_{H}-q_{L}\right)}$, with $e_{\max }^{t E}>e_{\min }^{t E}$.

We summarize the optimal tax policy in the following remark.

Remark 3 Depending on the value taken by the polluting emission $e$, the government optimally sets: (i) $t=0$ when $e<e_{\min }^{t E} \cup b \in\left(b_{\min }^{E}, \widehat{b}\right)$; (ii) $t=t^{* E}$ when $e \in\left[e_{\min }^{t E}, e_{\max }^{t E}\right) \cup b \in\left(b_{\min }^{E}, \widehat{b}\right)$ and when $e \in\left[0, e_{\max }^{t E}\right) \cup b>\widehat{b}$ (iii) $t=t_{\max }^{E}$ when $e \geq e_{\max }^{t E}$.

Notice that when $t=t_{\max }^{E}$, the profit of the low quality firm tends to zero. Using the same reasoning as in the previous case, it is relatively easy to prove that the government would prefer to leave an $\varepsilon \rightarrow 0$ to the polluting firm, and then keep the duopoly, instead of pushing the firm out of the market. The expressions for the social welfare for the three different values of $t$ which appear in Remark 3 are in the Appendix (see Proof of Proposition 2).

\subsection{Supporting the environmental campaign}

Assume that the policy maker implements a campaign that creates a social stigma for brown $L$ consumers while at the same time praising green $H$ consumers. The utility from buying is then as follows:

$$
U(\theta)=\left\{\begin{array}{c}
\theta q_{H}-p_{H}+\gamma\left(q_{H}-q_{L}\right) \text { if she buys the green good } \\
\theta q_{L}-p_{L}-\gamma\left(q_{H}-q_{L}\right) \text { if she buys the brown good } \\
0 \text { if she refrains from buying. }
\end{array}\right.
$$


The consumer indifferent between buying the low quality good and not buying at all is:

$$
\theta_{L}=\frac{p_{L}+\gamma\left(q_{H}-q_{L}\right)}{q_{L}}
$$

The consumer indifferent between buying the low quality good and the high quality good is:

$$
\theta_{H}=\frac{p_{H}-p_{L}-2 \gamma\left(q_{H}-q_{L}\right)}{q_{H}-q_{L}}
$$

Notice that for given prices, relative preferences are such that the market share of $H$ increases in $\gamma$, as the consumer who is indifferent between not buying and buying $\mathrm{L}\left(\theta_{L}\right)$ moves to the right, while the consumer who is indifferent between buying $L$ and $H\left(\theta_{H}\right)$ moves to the left.

Following the previous discussion, the demands for the goods are therefore given by $x_{L}=\theta_{H}-\theta_{L}$ and $x_{H}=b-\theta_{H}$. Again, we assume that producing the green good implies higher costs than the brown good $(c>0)$. Profits are then $\pi_{H}=x_{H}\left(p_{H}-c\right)$ and $\pi_{L}=p_{L} x_{L}$. Price competition yields:

$$
\begin{aligned}
p_{L}^{* * E} & =\frac{q_{L}\left[c+b\left(q_{H}-q_{L}\right)\right]-2 \gamma q_{H}\left(q_{H}-q_{L}\right)}{4 q_{H}-q_{L}}, \\
p_{H}^{* * E} & =\frac{2 c q_{H}+\left(q_{H}-q_{L}\right)\left[2 b q_{H}+\gamma\left(3 q_{H}-q_{L}\right)\right]}{4 q_{H}-q_{L}} .
\end{aligned}
$$

The following condition is compatible with the basic assumptions of the model:

Lemma 7 The market is uncovered and both firms stay in the market iff $b>b_{\min }^{E}$ and $\gamma<$ $\frac{q_{L}\left[c+b\left(q_{H}-q_{L}\right)\right]}{2 q_{H}\left(q_{H}-q_{L}\right)} \equiv \gamma_{\max }^{E}$

Proof. See the Appendix.

Equilibrium demands/outputs are:

$$
\begin{aligned}
x_{L}^{* * E} & =\frac{q_{H}\left\{q_{L}\left[c+b\left(q_{H}-q_{L}\right)\right]-2 \gamma q_{H}\left(q_{H}-q_{L}\right)\right\}}{\left(q_{H}-q_{L}\right)\left(4 q_{H}-q_{L}\right) q_{L}} \\
x_{H}^{* * E} & =\frac{\left[\gamma\left(3 q_{H}-q_{L}\right)+2 b q_{H}\right]\left(q_{H}-q_{L}\right)-c\left(2 q_{H}-q_{L}\right)}{\left(q_{H}-q_{L}\right)\left(4 q_{H}-q_{L}\right)} .
\end{aligned}
$$

As before, notice that $x_{L}$ decreases with $\gamma$, while $x_{H}$ increases with $\gamma$. However, overall total output now decreases with $\gamma$, meaning that the environmental campaign is not a priori increasing consumer surplus.

Equilibrium profits are now given by:

$$
\begin{aligned}
\pi_{L}^{* * E} & =\frac{q_{L}}{q_{H}}\left(q_{H}-q_{L}\right)\left(x_{L}^{* *}\right)^{2} \\
\pi_{H}^{* * E} & =\left(q_{H}-q_{L}\right)\left(x_{H}^{* *}\right)^{2}
\end{aligned}
$$

The social welfare function writes in a compact way as :

$$
S W^{* * E}(\gamma)=\pi_{L}^{* E}+\pi_{H}^{* E}+C S_{L}^{* E}+C S_{H}^{* E}-e \cdot x_{L}^{* E}-s \frac{\gamma^{2}}{2}
$$


where $s$ is the marginal cost of the campaign. The social welfare function is concave in $\gamma$ if and only if $s>s_{\min }$, where $s_{\min }$ is defined in (8). In this case it is possible to compute the optimal level of $\gamma$ that maximizes social welfare:

$$
\gamma^{* E}=\frac{2 e q_{H}^{2}\left(4 q_{H}-q_{L}\right)+q_{L}\left[2 c\left(6 q_{H} q_{L}-10 q_{H}^{2}-q_{L}^{2}\right)+b q_{H}\left(8 q_{H}-3 q_{L}\right)\left(q_{H}-q_{L}\right)\right]}{s q_{L}\left(4 q_{H}-q_{L}\right)^{2}-\left(q_{H}-q_{L}\right)\left(12 q_{H}^{3}+2 q_{L}^{3}-13 q_{H} q_{L}^{2}+19 q_{H}^{2} q_{L}\right)} .
$$

Taking into account that $\gamma^{* E}$ has to be non-negative and that the the conditions reported in Lemma 7 have to be satisfied, we find:

Lemma $8 \gamma^{*} \in\left[0, \gamma_{\max }^{E}\right)$ when $e \in\left[\max \left\{0, e_{\min }^{\gamma E}\right\}, e_{\max }^{\gamma E}\right)$.

Proof. See the Appendix.

We summarize the optimal environmental policy in the following remark.

Remark 4 Depending on the value taken by the polluting emission $e$, the government optimally sets: (i) $\gamma=0$ when $e<e_{\min }^{\gamma E} \cup b \in\left(b_{\min }, \widetilde{b}\right)$; (ii) $\gamma=\gamma^{* E}$ when $e \in\left[e_{\min }^{\gamma E}, e_{\max }^{\gamma E}\right) \cup b \in\left(b_{\min }^{E}, \widetilde{b}\right)$ and when $e \in\left[0, e_{\max }^{\gamma E}\right) \cup b>\widetilde{b}$; (iii) $t=t_{\max }^{E}$ when $e \geq e_{\max }^{\gamma E}$.

The threshold value $\widetilde{b}$ can be found in the Appendix (Proof of Proposition 8), as well as the complete expression for the social welfare in the three cases reported in Remark 4 (again in the Proof of Proposition 2). We can now compare the two scenarios to find out which policy instrument should be adopted by the government.

\subsection{Comparing the two instruments under environmental qualities}

As in the previous scenario, we need to rank the threshold values of $e$ that define the regions where different levels of social welfare occur. The ranking depends on parameters $b$ and $s$. In the Appendix we detail all the possible cases. The following proposition summarizes the most important results. Let

$$
\begin{gathered}
b_{1}=\frac{2 c\left(28 q_{H}^{4}-53 q_{H}^{3} q_{L}+36 q_{H}^{2} q_{L}^{2}-10 q_{H} q_{L}^{3}+q_{L}^{4}\right)}{q_{H}\left(4 q_{H}-3 q_{L}\right)\left(q_{H}-q_{L}\right)\left(10 q_{H}^{2}-6 q_{H} q_{L}+q_{L}^{2}\right)}, \\
b_{2}=\frac{2 c\left(2 q_{H}-q_{L}\right)^{2}}{q_{H}\left(4 q_{H}^{2}-7 q_{H} q_{L}+3 q_{L}^{2}\right)} .
\end{gathered}
$$

Proposition 2 Assume that consumers are environmentally concerned. The social welfare preferences are such that:

(i) for $b$ low values of $b\left(b \leq b_{1}\right)$, the tax instrument is socially more efficient than the environmental campaign.

(ii) For intermediate values of $b\left(b \in\left(b_{1}, b_{2}\right)\right)$, the tax instrument prevails as long as the cost of the campaign is sufficiently high. For a relatively low cost of the campaign, taxation dominates the campaign only if the quality ratio $q_{H} / q_{L}$ is not excessive. When the quality ratio is high, there exists a threshold level for the polluting emission above which the environmental campaign is preferred and under which taxation is preferred. 
(iii) For $b$ high values of $b\left(b \geq b_{2}\right)$, the environmental campaign is socially more efficient than the tax instrument, unless both the cost of the campaign and the emission levels are sufficiently high.

Proof. See the Appendix.

The results coming from the above proposition reveal that an indirect instrument as the environmental campaign can be more efficient than a direct tax levied on the brown good. The two preconditions for that to happen is that the cost of the campaign be not too excessive, and that the average evaluation of the environmental quality in the market be sufficiently high. While the first precondition is trivial, the second one is less obvious. In particular, it highlights that the green expansive effect of the environmental campaign increases in $b$ : the higher the average evaluation for the environmental quality in the market, the larger the number of consumers willing to buy the green good. Such an effect implies that, for a given cost $s$, an increase in $b$ increases the effectiveness of the campaign in reducing the polluting emissions.

Therefore, for low values of $b$, the green expansive effect is almost irrelevant, and taxing the polluting product is preferred from the social standpoint. In contrast, for high values of $b$, then such an effect becomes crucial and the campaign turns out to be more efficient than the taxation instrument, provided its cost is not exaggerated.

Finally, when $b \in\left(b_{1}, b_{2}\right)$, the green expansion effect is intermediate and the comparison between the two instruments includes more elements which can either tend to reinforce or to stifle the relevancy of such an effect. Again, taxation prevails in terms of efficiency when $s$ is high. On the contrary, when the campaign is relatively affordable, we find that the quality ratio $q_{H} / q_{L}$ may compensate for b. In particular, when $q_{H} / q_{L}$ is sufficiently high, meaning that the brown good is very distant from the green good in terms of the quality perceived by environmentally concerned consumers, then the campaign can be welfare improving as compared to the tax instrument, especially if the polluting damage is severe (i.e. if $e$ exceeds a certain value). The explanation relies on the fact that a relatively inexpensive campaign can reduce the consumption of a good whose (environmental) quality is very low, and this is even more important when the external emission released by such good is very polluting.

Moreover, it is worth noticing that a relatively high emission level $e$ can determine a preference for the taxation instrument, when the campaign is sufficiently costly. The role of $e$ is therefore ambiguous:

Corollary 1 When $b \geq b_{1}$, a high emission level may favor the adoption of the campaign if its cost is low, while it may induce the social planner to tax the polluting good if the cost of the campaign is high.

Hence, depending on the cost of the campaign, a high emission level can determine whether the policy maker should adopt the environmental campaign or the taxation instrument. When $b \in\left(b_{1}, b_{2}\right)$ taxation is usually preferred given that consumers' heterogeneity is limited. However, 
when the quality ratio is very high, the brown good is perceived of very poor quality: a high emission level may then convince the policy maker to implement the campaign instead of taxing the polluting good, provided the cost of the campaign is not excessive. On the contrary, when $b \geq b_{2}$, if the campaign is costly, then taxation prevails when pollution increases.

\section{A tale of two worlds}

The purpose of our paper was to examine social welfare under two different policy instruments, both aiming at reducing pollution emissions, in two different "worlds", one populated by environmentally conscious citizens, while the other by those indifferent to environmental issues.

The main conclusion that one can draw when comparing Proposition 1 with Proposition 2 is that consumers' preliminary sensitivity towards the environment is a necessary condition for the environmental campaign to prove more efficient than the pollution tax. Remember that we evaluate the relative performance of the two instruments on the basis of total social welfare. In both our "worlds", the environmental campaign is indeed effective in reducing the pollution emissions. Indeed, it shifts the buying decision of (at least) some consumers from the brown to the green good, independently of consumers' concern about the environment. However, when compared to other instruments like the pollution tax, the campaign may not be the welfare maximizing policy when the environmental concern is low.

In our model, in fact, such a preliminary concern affects the same definition of quality. When consumers are environmentally indifferent, for example, they tend to measure the quality in terms of the intrinsic performance of a product. The green expansive effect generated by the campaign is therefore weak, and it does not compensate for the cost required to support the campaign itself. A traditional instrument like the pollution tax, which is directly levied on the production of the polluting good, turns out to be more efficient. In addition, it represents a net gain for the government. For the environmental campaign to be also socially efficient, we need a scenario in which the market evaluation of the environmental quality is sufficiently high.

In real world terms, this translates into different environmental policies adopted in different countries. Extreme examples of what we have in mind are provided by Sweden and China. While the former is an early adopter of sustainable thinking and one of the few industrialized countries to have reduced its carbon emissions, ${ }^{13}$ the latter may well represent an example of a country where environmental protection is not a main concern. Empirical support for our statement comes from the Eurostat statistics on EU countries' tax revenues on pollution as a percentage of GDP: in 2011 the EU average was 0.11, while Sweden was well below this value (0.05). ${ }^{14}$ China, on the contrary, suffers

\footnotetext{
${ }^{13}$ Back in the $1960 \mathrm{~s}$, Sweden recognised that the rapid loss of natural resources had to be confronted, and took a lead in organising the first UN conference on the environment, held in Stockholm in 1972. For further details on Swedish environmental policies, visit www.sweden.se/eng/Home/Society/Sustainability/Facts/Environment.

${ }^{14}$ Clearly, these numbers cannot be taken as strong evidence supporting our results, given that a low tax revenue in a country could also be due to tax evasion or simply a mild environmental policy by that government. However, at least looking at Sweden (and Finland as well with 0.06) we can reasonably conclude that this is linked to a strong environmental concern of consumers.
} 
from severe environmental damages to natural resources associated with the country's rapid economic successes. ${ }^{15}$ Recent measures taken by the Chinese government aims at improving its environmental situation. However, this is mainly done by resorting to traditional policy instruments. ${ }^{16}$

We would like to point out that our policy implications are based on total social welfare as a measure of a social well-being. While this is a quite standard measure of welfare, a policy maker may decide to put different weights on consumer and producer surplus when evaluating a policy intervention. Our results may therefore change if we consider consumer surplus as an alternative measure of welfare. Indeed, as put forward in the model, taxation shrinks total output, thus implying that consumer surplus decreases when the government applies such a tool. This holds under both hedonic and environmental preferences. As for the environmental campaign, it has a similar effect but only with environmental preferences. Under hedonic preferences, on the contrary, the effect of the campaign is to increase total output, thus expanding consumer surplus. This means that if one attaches a relatively high weight to consumer surplus, then the environmental campaign may surpass the taxation instrument in terms of efficiency even if consumers are environmentally unconcerned.

\subsection{Discussion on the assumptions}

It is worth discussing the main technical assumptions of our model in order to check the robustness of our results. The first assumption is related to the existence of two "worlds"; one characterized by hedonic preferences and the other by environmental preferences. We acknowledge that this implies two polarized scenarios, and that in any society we find environmentally concerned consumers together with unconcerned one. Hence, usually these two "worlds" coexist in the same city, country, and region. However, the separation that we adopt in our theoretical representation is crucial to understand which policy is socially preferable among these different consumers. Clearly, there exists a continuum of intermediate scenarios where, for instance, a fraction $\alpha$ of consumers is environmentally unconcerned, whereas the complementary fraction $(1-\alpha)$ is environmentally concerned. We believe, that, while this may represent an interesting extension of our modeling strategy, it would not add much to our point. Our guess is that there would be an $\alpha$-threshold such that the campaign would prove to be more efficient than the tax instrument as long as the fraction of environmentally concerned consumers is sufficiently high (and viceversa).

Secondly, we assume that the cost of the environmental campaign is sufficiently high $\left(s>s_{\min }\right)$ : this ensures that the social welfare function is concave in the environmental campaign $(\gamma)$. This allows us to find, for intermediate emission levels, the optimal level of the environmental campaign. For $s<s_{\min }$, the social welfare function is convex in $\gamma$, meaning that the optimal campaign level is reached either in $\gamma=0$ or in $\gamma=\gamma_{\max }$. Considering hedonic preferences, it is possible to demonstrate that, when $s<s_{\min }$, there are conditions for which a relatively cheaper campaign can be more more

\footnotetext{
${ }^{15}$ China recently became the world's second largest economy by aggregate GNP.

${ }^{16}$ See for instance a recent press article in The Guardian pointing out China's new five-year cleanup strategy based on environmental tax on heavy polluters. For more information, visit www.theguardian.com/world/2011/feb/04/chinagreen-tax-polluters.
} 
efficient than the pollution tax. In particular, this is more likely to happen for relatively high values of parameter $b$, i.e. when consumers' ex-ante heterogeneity is prominent. However, as both goods are still on the market, the emission level should not be perceived as too dangerous by the social planner, otherwise a more direct taxation instrument is to be preferred. ${ }^{17}$ In contrast, in the environmental preferences scenario our qualitative results do not change, and the campaign is, a fortiori, more efficient than the tax instrument in most cases.

Thirdly, notice that we restrict our attention to sufficiently low levels of the environmental campaign: this assumption ensures that both firms stay in the market and that the initial quality ranking does not reverse. In particular, in the environmental preferences scenario, the threshold value of $\gamma$ $\left(\gamma_{\max }\right)$ is such that, beyond this value, the low (brown) quality firm would be inactive in the market. In contrast, in the hedonic preferences scenario, the threshold value of $\gamma\left(\gamma_{\max }\right)$ is such that, again beyond this value, the low (green) quality firm would become the high quality one. That is, we would observe, due to the effect of the campaign, a switch in the hedonic qualities. ${ }^{18}$ In other words, in order to keep the initial hedonic qualities' ranking, we assume that the campaign cannot be too "revolutionary". Notice, however, that our results are robust to this assumption. Indeed, in the environmental preferences scenario, it would not make sense to further pursue the campaign. Once the brown firm is pushed off the market, then the emissions reach their minimal level. On the other hand, in the hedonic preferences scenario, extending the analysis to comprehend higher levels of $\gamma$ would alter the equilibrium market structure. In particular, this would imply passing first from an uncovered to a covered duopoly market (at the limit), and then to a monopoly dominated by the low green quality firm. Yet again, our main result would hold. For environmentally unconcerned consumers, the tax instrument would remain more efficient than the campaign. In fact, recall that pursuing high levels of the environmental campaign would require increasing costs.

\section{Conclusions}

In this paper we have considered two different worlds, depending on whether consumers' preferences are ex ante affected by environmental concerns or not. The first world deals with consumers who value only the intrinsic quality of the good. The second one is instead characterized by consumers who appreciate the environmental sustainability more than the pure performance of the purchased good . The automotive industry, for instance, provides various case studies in support of the two different theoretical scenarios that we represented. Consumers, in fact, tend to have different valuations regarding the performance of the vehicle as compared its environmental impact.

In both cases, we have studied the adoption of two different policies by the social planner/government. The conventional tax on the emission of pollution has been compared with an environmental cam-

\footnotetext{
${ }^{17}$ The comparison between the different social welfares when $s \leq s_{\min }$ is not present in the Appendix. As the Proof of Proposition 1 is already very long, we decided to skip the formal demonstration of ancillary results which are not at the core of our paper. They are, however, available upon request.

${ }^{18}$ Technically, the equilibrium price of the high brown quality good would be lower than the equilibrium price of the low green quality good but still both goods would stay in the market.
} 
paign which aimed at stigmatizing the polluting (brown) good. By design, both policy instruments are effective in reducing the polluting emissions. However, their efficiency from a social welfare point of view changes accordingly to consumer environmental concern. More precisely, in case of environmentally unconcerned consumers, the tax instrument reveals to be more efficient than the environmental campaign, whereas the opposite may occur when consumers value the environmental quality of the goods.

In the previous section, we have also discussed the robustness of the main assumptions of our model, together with its main limitations. Nonetheless, we believe that our paper may represent an interesting starting point in order to evaluate the relative performance of environmental campaign vis à vis traditional policy instruments. Moreover, additional theoretical and empirical research must be carried out with the aim of providing accurate results, thereby helping the policy maker in the design of the best suited instrument for social welfare in order to curb pollution emission.

On the theoretical ground, an interesting extension of our research concerns the potential dynamic efficiency of the campaign itself. Consider, for instance, an initial scenario where consumers are characterized by hedonic preferences. Although environmental campaigns may not pay off in the short term, they may gradually become ingrained in the social consciousness, thereby providing a foundation for the success of future campaigns. Thus, we should compare the static efficiency of the tax instrument with the dynamic efficiency of the environmental campaign. Related to this issue, we may also think of using dynamic models to capture the idea that the cost of the campaign could decrease over time.

\section{Appendix}

\section{Proof of Lemma 1}

We focus on the case in which the price of the high quality good is higher than that of the low quality:

$$
p_{H}-p_{L} \geqslant 0 \Longleftrightarrow t>\frac{c q_{H}}{2 q_{H}-q_{L}}-b\left(q_{H}-q_{L}\right) \equiv \widetilde{t} .
$$

Moreover, we have to guarantee that at these equilibrium prices both firms are active in the market. This implies that we have to simultaneously satisfy the conditions for which $0<\theta_{L}<\theta_{H}<b$. We obtain:

$$
\begin{aligned}
\theta_{L} & =\frac{q_{L} b\left(q_{H}-q_{L}\right)+t q_{L}+2 c q_{H}}{\left(4 q_{H}-q_{L}\right) q_{L}}>0, \text { always; } \\
\theta_{H}-\theta_{L} & >0 \Longleftrightarrow t>\frac{c\left(2 q_{H}-q_{L}\right)-b q_{L}\left(q_{H}-q_{L}\right)}{q_{L}} \equiv t_{\min } \\
\theta_{H}-b & <0 \Longleftrightarrow t<\frac{q_{H}\left[2 b\left(q_{H}-q_{L}\right)+c\right]}{\left(2 q_{H}-q_{L}\right)} \equiv t_{\max } .
\end{aligned}
$$

It is easy to demonstrate that $t_{\min }>\widetilde{t}$, and then $p_{H}>p_{L}$ when $\theta_{H}>\theta_{L}$. Moreover, $t_{\min }<0 \Longleftrightarrow$ $b>\frac{c\left(2 q_{H}-q_{L}\right)}{q_{L}\left(q_{H}-q_{L}\right)} \equiv b_{\min }$. It is convenient to assume that $b>b_{\min }$ in order to eliminate the condition 
$t>t_{\min }$. This reduces the number of cases to be examined, without losing economic intuition. By combining the previous conditions, it follows that condition $b>b_{\min }$ combined with $t<t_{\max }$ are required to have both players active in an uncovered market.

\section{Proof of Lemma 3}

To start with, notice that

$$
p_{H}-p_{L}>0 \Longleftrightarrow \gamma<\frac{b\left(2 q_{H}-q_{L}\right)\left(q_{H}-q_{L}\right)-c q_{H}}{\left(5 q_{H}-q_{L}\right)\left(q_{H}-q_{L}\right)} .
$$

This threshold value of $\gamma$ decreases in $c$ and increases in $b$. On the one hand, the higher $c$ is, the lower the value which guarantees that both goods are in the market, that is the more stringent the constraint because $p_{L}$ becomes increasingly higher than $p_{H}$. On the other hand, the higher parameter $b$ is, the higher the threshold for $\gamma$ for both goods to stay in the market, that is the less binding the constraint because consumers become increasingly heterogeneous and competition softens. ${ }^{19}$

We have to check whether at the equilibrium prices both firms are in the market, i.e. we need to verify that $0<\theta_{L}<\theta_{H}<b$ :

$$
\begin{aligned}
\theta_{L} & =\frac{2 c q_{H}+\left(q_{H}-q_{L}\right)\left[b q_{L}-\gamma\left(2 q_{H}+q_{L}\right)\right]}{\left(4 q_{H}-q_{L}\right) q_{L}}>0 \Longleftrightarrow \gamma<\frac{2 c q_{H}+b\left(q_{H}-q_{L}\right) q_{L}}{\left(q_{L}-2 q_{H}\right)\left(q_{L}-q_{H}\right)}, \\
\theta_{H}-\theta_{L} & =\frac{q_{H}\left[c\left(q_{L}-2 q_{H}\right)+\left(q_{H}-q_{L}\right)\left(b q_{L}+2 \gamma q_{H}\right)\right]}{\left(q_{L}-q_{H}\right)\left(q_{L}-4 q_{H}\right) q_{L}}>0 \text { always when } b>b_{\text {min }}, \\
\theta_{H}-b & =\frac{\left(q_{L}-q_{H}\right)\left[2 b q_{H}-\gamma\left(3 q_{H}-q_{L}\right)\right]-c q_{H}}{\left(q_{L}-q_{H}\right)\left(q_{L}-4 q_{H}\right)}<0, \text { always when } p_{H}-p_{L}>0 .
\end{aligned}
$$

Assuming that $b>b_{\min }$, we need therefore only to compare the two threshold values of $\gamma$. This comparison depends on $b$. However, as we will demonstrate that exactly the same results appear when using one of the two values, we can use $\gamma_{\max }=\min \left\{\frac{b\left(2 q_{H}-q_{L}\right)\left(q_{H}-q_{L}\right)-c q_{H}}{\left(5 q_{H}-q_{L}\right)\left(q_{H}-q_{L}\right)}, \frac{2 c q_{H}+b\left(q_{H}-q_{L}\right) q_{L}}{\left(q_{L}-2 q_{H}\right)\left(q_{L}-q_{H}\right)}\right\}$.

\section{Proof of Lemma 4}

From (9), $\gamma^{*} \geq 0$ iff $e \geq e_{\min }^{\gamma}=\frac{q_{H}\left[q_{L} b\left(3 q_{L}-8 q_{H}\right)\left(q_{L}-q_{H}\right)-c\left(q_{L}-3 q_{H}\right)\left(4 q_{H}+q_{L}\right)\right]}{q_{L}\left(q_{L}-4 q_{H}\right)\left(q_{L}-3 q_{H}\right)}$. If $\gamma_{\max }=\frac{b\left(2 q_{H}-q_{L}\right)\left(q_{H}-q_{L}\right)-c q_{H}}{\left(5 q_{H}-q_{L}\right)\left(q_{H}-q_{L}\right)} \equiv \gamma_{\max }^{1}$, we have that $\gamma^{*}<\gamma_{\max }$ when $e<e_{\max }^{\gamma}=\frac{\left(q_{H}-q_{L}\right)\left(18 c q_{H}^{3}-6 b q_{H}^{4}+2 b q_{L}^{4}-8 b q_{H} q_{L}^{3}+8 b q_{H}^{3} q_{L}-3 c q_{H} q_{L}^{2}+5 c q_{H}^{2} q_{L}+4 b q_{H}^{2} q_{L}^{2}\right)+s q_{L}\left(4 q_{H}-q_{L}\right)\left(2 b q_{H}^{2}-3 b q_{H} q_{L}-c q_{H}+b q_{L}^{2}\right)}{q_{L}\left(3 q_{H}-q_{L}\right)\left(q_{L}-q_{H}\right)\left(q_{L}-5 q_{H}\right)} ;$ while if $\gamma_{\max }=\frac{2 c q_{H}+b\left(q_{H}-q_{L}\right) q_{L}}{\left(q_{L}-2 q_{H}\right)\left(q_{L}-q_{H}\right)} \equiv \gamma_{\max }^{2}$ we have that $\gamma^{*}<\gamma_{\max }$ when $e<e_{\max }^{\gamma}=\frac{\left(q_{H}-q_{L}\right)\left(13 c q_{H}^{2}-b q_{H}^{3}-3 c q_{H} q_{L}+2 b q_{L}^{3}-10 b q_{H} q_{L}^{2}+9 b q_{H}^{2} q_{L}\right)+s\left(4 q_{H}-q_{L}\right)\left(b q_{L}^{2}-b q_{H} q_{L}-2 c q_{H}\right)}{\left(q_{H}-q_{L}\right)\left(q_{L}-2 q_{H}\right)\left(3 q_{H}-q_{L}\right)}$.

\footnotetext{
${ }^{19}$ If $\gamma$ is high relative to $b$ or $b$ is low relative to $\gamma$ the high quality good goes out of the market: even the highest quality oriented consumer (which is $b$ ) will buy the low quality green good. The same hold when $b$ is low relative to $\gamma$, in fact the higher $\mathrm{b}$ the more heterogeneous are consumers and so the more difficult that the market is served by only one quality.
} 


\section{Proof of Proposition 1}

First of all, when taxing the polluting good, remember that the social welfare function appears in (3), where:

$$
\begin{aligned}
C S_{L}^{*} & =\int_{\theta_{L}}^{\theta_{H}}\left(\theta q_{L}-p_{L}\right) d \theta=\frac{\left(x_{L}^{*}\right)^{2}}{2} \cdot q_{L}, \\
C S_{H}^{*} & =\int_{\theta_{H}}^{b}\left(\theta q_{H}-p_{H}\right) d \theta=x_{H}^{*} \cdot \frac{q_{H}\left[2 b\left(q_{H}^{2}-q_{L}^{2}\right)-c\left(3 q_{H}-2 q_{L}\right)-t\left(2 q_{H}-q_{L}\right)\right]}{\left(4 q_{H}-q_{L}\right)\left(q_{H}-q_{L}\right)} .
\end{aligned}
$$

The optimal tax rate $t^{*}$ which maximizes social welfare appears in (4), and from Lemma 1 we know that $t^{*} \in\left[0, t_{\max }\right)$ when $e \in\left[e_{\min }^{t}, e_{\max }^{t}\right)$. Hence, as reported in Remark 1 , the government sets: (i) $t=0$ when $e<e_{\min }^{t}$; (ii) $t=t^{*}$ when $e \in\left[e_{\min }^{t}, e_{\max }^{t}\right.$ ); (iii) $t=t_{\max }$ when $e \geqslant e_{\max }^{t}$. By substituting into (3), we have:

$$
\begin{aligned}
&\left.S W\right|_{t=0}= \frac{q_{H}}{2 q_{L}\left(4 q_{H}-q_{L}\right)^{2}\left(q_{H}-q_{L}\right)}\left\{c^{2}\left(12 q_{H}^{2}-9 q_{H} q_{L}+2 q_{L}^{2}\right)\right. \\
&-2 c q_{L}\left[4 q_{H}\left(e+b q_{H}\right)-q_{L}\left(e+6 b q_{H}-2 b q_{L}\right)\right] \\
&\left.-b\left(q_{H}-q_{L}\right) q_{L}\left[4 e\left(4 q_{H}-q_{L}\right)+b\left(12 q_{H}^{2}-q_{H} q_{L}-2 q_{L}^{2}\right)\right]\right\}, \\
&\left.S W\right|_{t=t^{*}}=\frac{1}{24}\left[4\left(\frac{e^{2}}{q_{H}}+3 b^{2} q_{H}-6 b e\right)+\frac{12(e-c)^{2}}{\left(q_{H}-q_{L}\right)}+\frac{9 c^{2}}{q_{L}}-\frac{(3 c-4 e)^{2}}{4 q_{H}-q_{L}}\right], \\
&\left.S W\right|_{t=t_{\max }}=\frac{q_{H}\left(3 q_{H}-2 q_{L}\right)\left(c-b q_{L}\right)^{2}}{2 q_{L}\left(2 q_{H}-q_{L}\right)^{2}} .
\end{aligned}
$$

Second, when activating the campaign, the social welfare function as a function of $\gamma$ is given by (7), where:

$$
\begin{aligned}
C S_{L}^{* *} & =\int_{\theta_{L}}^{\theta_{H}}\left[\left(\theta q_{L}-p_{L}\right)+\gamma\left(q_{H}-q_{L}\right)\right] d \theta=\frac{\left(x_{L}^{* *}\right)^{2}}{2}, \\
C S_{H}^{* *} & =\int_{\theta_{H}}^{b}\left[\left(\theta q_{H}-p_{H}\right)-\gamma\left(q_{H}-q_{L}\right)\right] d \theta=\frac{\left(x_{H}^{* *}\right)^{2}}{2} \cdot q_{H}\left[(2 b+\gamma)\left(q_{H}^{2}-q_{L}^{2}\right)-c\left(3 q_{H}+2 q_{L}\right)\right] .
\end{aligned}
$$

The optimal $\gamma^{*}$ appears in (9); by combining the results in Lemma 4 with the considerations reported in Remark 2, we obtain that, by substituting into (7):

$$
\left.S W\right|_{\gamma=0}=\left.S W\right|_{t=0} \text { by construction, }
$$




$$
\begin{aligned}
\left.S W\right|_{\gamma=\gamma^{*}}= & \frac{1}{2\left(q_{L}-q_{H}\right)\left[\left(q_{L}-q_{H}\right)\left(12 q_{H}^{3}+2 q_{L}^{3}-13 q_{H} q_{L}^{2}+19 q_{H}^{2} q_{L}\right)-q_{L}\left(4 q_{H}-q_{L}\right)^{2} s\right]}\{ \\
& 2 c q_{H}\left(q_{H}-q_{L}\right)^{2}\left[e\left(6 q_{H}-q_{L}\right)\right]-2 b c q_{H}\left(9 q_{H}-4 q_{L}\right)\left(q_{H}+q_{L}\right)+8 c q_{H}^{2} q_{L}\left(e+b q_{H}\right) \\
& \left.-2 c q_{H} q_{L}\left(e+6 b q_{H}\right) q_{L}+2 b q_{L}^{2}\right) s+\left(q_{H}-q_{L}\right)\left[b^{2} q_{H}\left(9 q_{H}-4 q_{L}\right)\left(q_{H}-q_{L}\right)\left(q_{L}+q_{H}\right)^{2}\right] \\
+ & c^{2} q_{H} \cdot\left[\left(9 q_{H}-4 q_{L}\right)\left(q_{H}+q_{L}\right)^{2}-s\left(12 q_{H}^{2}-9 q_{H} q_{L}+2 q_{L}^{2}\right)\right]+ \\
+ & \left(q_{H}-q_{L}\right)\left[b q_{H} q_{L}\left(16 e q_{H}-12 b q_{H}^{2}-4 e q_{L}+b q_{H} q_{L}+2 b q_{L}^{2}\right) s\right] \\
- & \left.\left(q_{H}-q_{L}\right) e^{2} q_{L}\left(3 q_{H}-q_{L}\right)^{2}+2 b e q_{H}\left(q_{H}-q_{L}\right)\left(6 q_{H}-q_{L}\right)\left(q_{H}+q_{L}\right)\right\}, \\
\left.S W\right|_{\gamma=\gamma_{\max }=} & \frac{1}{2 q_{L}\left(5 q_{H}^{2}-9 q_{H} q_{L}+2 q_{L}^{2}\right)}\left\{c q_{H}\left[27 q_{H}^{3}-36 q_{H}^{2} q_{L}-2 q_{L}^{3}+q_{H} q_{L}\left(11 q_{L}-s\right)\right]\right. \\
& +b \cdot\left(q_{H}-q_{L}\right)^{2}\left(q_{H}+q_{L}\right)\left[b\left(q_{H}+q_{L}\right)\left(3 q_{H}^{2}+3 q_{H} q_{L}-2 q_{L}^{2}\right)-2 e q_{L}\left(5 q_{H}-q_{L}\right)\right] \\
& -b q_{L}\left(2 q_{H}^{2}-3 q_{H} q_{L}+q_{L}^{2}\right)^{2} s-4 c q_{H} q_{L}\left(q_{H}-q_{L}\right)\left(5 q_{H}-q_{L}\right) e \\
& \left.\quad-2 b c q_{H}\left(q_{H}-q_{L}\right)\left[9 q_{H}^{2}-5 q_{H}^{2} q_{L}+q_{L}^{2}\left(5 q_{L}+s\right)-q_{H} q_{L}\left(9 q_{L}+2 s\right)\right]\right\} .
\end{aligned}
$$

For exposition purposes, we limit our attention to the case when $\gamma_{\max }=\gamma_{\max }^{1}$. However, tedious numerical calculations show that the same results would hold even when considering $\gamma_{\max }=\gamma_{\max }^{2}$.

Now we can prove the main results of Proposition 1 . When $s>s_{\min }$, by comparing the different $e$-thresholds one can find the following three cases.

- When $b \in\left(b_{\min }, \widetilde{b}\right)$, with $b_{\min }$ defined in $(1)$ and $\widetilde{b}=\frac{c\left(3 q_{H}-q_{L}\right)\left(16 q_{H}^{3}-24 q_{H}^{2} q_{L}+11 q_{H} q_{L}^{2}-q_{L}^{3}\right)}{q_{H}\left(q_{H}-q_{L}\right) q_{L}\left(16 q_{H}^{2}-20 q_{H} q_{L}+5 q_{L}^{2}\right)}$, the ranking is as follows:

$$
e_{\min }^{t}<e_{\max }^{t}<e_{\min }^{\gamma}<e_{\max }^{\gamma}
$$

- When $b>\widetilde{b}$ and $s \in\left(s_{\min }, \widetilde{s}\right)$, with $s_{\min }$ defined in $(8)$ and

$$
\widetilde{s}=\frac{\left(q_{H}-q_{L}\right)\left\{c q_{H}\left(97 q_{H}^{3} q_{L}-72 q_{H}^{4}-40 q_{H}^{2} q_{L}^{2}+2 q_{H} q_{L}^{3}+q_{L}^{4}\right)+b\left(q_{H}-q_{L}\right)\left(3 q_{H}-q_{L}\right)\left(8 q_{H}^{4}+12 q_{H}^{3} q_{L}-25 q_{H}^{2} q_{L}^{2}+11 q_{H} q_{L}^{3}-2 q_{L}^{4}\right)\right\}}{q_{L}\left(4 q_{H}-q_{L}\right)\left(2 q_{H}-q_{L}\right)^{2}\left[b\left(q_{L}-2 q_{H}\right)\left(q_{L}-q_{H}\right)-c q_{H}\right]}
$$

the ranking is:

$$
e_{\min }^{t}<e_{\min }^{\gamma}<e_{\max }^{\gamma}<e_{\max }^{t}
$$

- Finally, for $b>\widetilde{b}$ and $s>\widetilde{s}$, we have that:

$$
e_{\min }^{t}<e_{\min }^{\gamma}<e_{\max }^{t}<e_{\max }^{\gamma}
$$

Comparing the appropriate social welfare expressions, we can prove that, for any emission level $e$, taxation always determines a higher welfare than the environmental campaign. In order to provide a sketch of the proof, let us start from the first interval region, in which $b \in\left(b_{\min }, \widetilde{b}\right)$. Four subintervals have to considered, depending on the emission level: ${ }^{20}$

\footnotetext{
${ }^{20}$ The case $e \in\left(0, \min \left\{e_{\min }^{t}, e_{\min }^{\gamma}\right\}\right)$ can be disregarded, as no policy instrument is adopted, and therefore $\left.S W\right|_{\gamma=0}-$ $\left.S W\right|_{t=0}=0$.
} 
1. For $e \in\left(e_{\min }^{t}, e_{\max }^{t}\right)$, we compare $\left.S W\right|_{\gamma=0}$ with $\left.S W\right|_{t=t^{*}}$; the result is $\left.S W\right|_{\gamma=0}-\left.S W\right|_{t=t^{*}}<0$.

2. For $e \in\left(e_{\max }^{t}, e_{\min }^{\gamma}\right),\left.S W\right|_{\gamma=0}-\left.S W\right|_{t=t_{\max }}<0$.

3. In $e \in\left(e_{\min }^{\gamma}, e_{\max }^{\gamma}\right)$, by evaluating $\left.S W\right|_{\gamma=\gamma^{*}}$ vis à vis $\left.S W\right|_{t=t^{*}}$ we find $\left.S W\right|_{\gamma=\gamma^{*}}-\left.S W\right|_{t=t_{\max }}<$ 0 .

4. Finally, also in $e>e_{\max }^{\gamma}$ the taxation instrument prevails, as $\left.S W\right|_{\gamma=\gamma_{\max }}-\left.S W\right|_{t=t_{\max }}<0$.

The precise expressions of the welfare comparisons are very long and are not reported in the text. They are available upon request with the list of the several numerical simulations that have been run to verify our results.

Similar results can be obtained when $b>\widetilde{b}$ and $s \in\left(s_{\min }, \widetilde{s}\right)$; we do not replicate all the welfare comparisons. However, the result is immediate to explain given that, ceteribus paribus, we are increasing the parameter $b$ which measures the average valuation of the hedonic quality in the market. Given that consumers attach even more importance to the vertical hedonic quality, a campaign that tries to make them aware of the environmental damage is less likely to function, and then taxation is even more efficient. Finally, in $b>\widetilde{b}$ and $s>\widetilde{s}$, the cost of the campaign is higher than in the previous interval regions, and therefore, a fortiori, this kind of policy is deemed to fail when compared to taxation.

\section{Proof of Lemma 5}

We focus on the case in which the price of the high quality good is higher than that of the low quality:

$$
p_{H}-p_{L}>0 \Longleftrightarrow t<\frac{2 b q_{H}^{2}-3 b q_{H} q_{L}+b q_{L}^{2}+c\left(2 q_{H}-q_{L}\right)}{q_{H}} \equiv \widehat{t}
$$

Moreover, we have to guarantee that at these equilibrium prices both firms stay in the market. This implies that we have to simultaneously satisfy conditions $0<\theta_{L}<\theta_{H}<b$ :

$$
\begin{aligned}
\theta_{L} & =\frac{p_{L}}{q_{L}}=\frac{\left(c q_{L}+2 t q_{H}+q_{L} b\left(q_{H}-q_{L}\right)\right)}{q_{L}\left(4 q_{H}-q_{L}\right)}>0 \\
\theta_{L}-\theta_{H} & =\frac{\left(c q_{L}-t\left(2 q_{H}-q_{L}\right)+b q_{H} q_{L}-b q_{L}^{2}\right) q_{H}}{\left(q_{H}-q_{L}\right)\left(q_{L}-4 q_{H}\right) q_{L}}<0 \Longleftrightarrow t<\frac{q_{L}\left[c+b\left(q_{H}-q_{L}\right)\right]}{\left(2 q_{H}-q_{L}\right)} \equiv t_{\max }^{E}<\widehat{t} \\
\theta_{H}-b & =\frac{\left(2 c q_{H}-c q_{L}-t q_{H}+2 b q_{H} q_{L}-2 b q_{H}^{2}\right)}{\left(q_{L}-q_{H}\right)\left(q_{L}-4 q_{H}\right)}<0 \Longleftrightarrow t>\frac{2 c q_{H}-c q_{L}+2 b q_{H} q_{L}-2 b q_{H}^{2}}{q_{H}} \equiv t_{\min }^{E} .
\end{aligned}
$$

However, it is easy to show that $t_{\text {min }}^{E}<0 \Longleftrightarrow b>\frac{2 c q_{H}-c q_{L}}{2 q_{H}\left(q_{H}-q_{L}\right)}=b_{\text {min }}^{E}$. 


\section{Proof of Lemma 7}

To start with, notice that:

$$
\begin{aligned}
p_{L} & >0 \Longleftrightarrow \gamma<\frac{q_{L}\left[c+b\left(q_{H}-q_{L}\right)\right]}{2 q_{H}\left(q_{H}-q_{L}\right)} \equiv \gamma_{\max }^{E}, \\
p_{H}-p_{L} & =\frac{\left(q_{L}-2 q_{H}\right)\left(b q_{L}-b q_{H}-c\right)+\gamma\left(q_{L}-5 q_{H}\right)\left(q_{L}-q_{H}\right)}{\left(4 q_{H}-q_{L}\right)}>0
\end{aligned}
$$

$\gamma_{\max }^{E}$ increases in $c$ and in $b$. Next, we have to check whether at the equilibrium prices both firms are in the market, i.e. we need to verify that $0<\theta_{L}<\theta_{H}<b$ :

$$
\begin{aligned}
\theta_{L} & =\frac{q_{L}\left(c+b q_{H}-b q_{L}\right)+\gamma\left(q_{L}-2 q_{H}\right)\left(q_{L}-q_{H}\right)}{\left(4 q_{H}-q_{L}\right) q_{L}}>0, \text { always } \\
\theta_{H}-\theta_{L} & >0 \Longleftrightarrow \gamma<\gamma_{\max }^{E}, \\
b-\theta_{H} & >0 \Longleftrightarrow \gamma>\frac{c\left(2 q_{H}-q_{L}\right)+2 q_{H} b\left(q_{L}-q_{H}\right)}{\left(q_{L}-3 q_{H}\right)\left(q_{L}-q_{H}\right)} \equiv \gamma_{\min }^{E}
\end{aligned}
$$

with $\gamma_{\min }^{E}>0 \Longleftrightarrow b<\frac{c\left(2 q_{H}-q_{L}\right)}{2 q_{H}\left(q_{H}-q_{L}\right)} \equiv b_{\min }^{E}$. Therefore, assuming that $b>b_{\min }^{E}$ implies that $\gamma_{\min }^{E}$ is negative and so $\theta_{H}<b$ always holds.

\section{Proof of Lemma 8}

Consider (15). First: $\gamma^{* E}>0 \Longleftrightarrow e>\frac{q_{L}\left(12 c q_{H} q_{L}+8 b q_{H}^{3}-20 c q_{H}^{2}-2 c q_{L}^{2}+3 b q_{H} q_{L}^{2}-11 b q_{H}^{2} q_{L}\right)}{2 q_{H}^{2}\left(4 q_{H}-q_{L}\right)} \equiv$ $e_{\min }^{\gamma E}$; however, $e_{\min }^{\gamma E}>0 \Longleftrightarrow b<\widetilde{b}=\frac{2 c\left(10 q_{H}^{2}-6 q_{H} q_{L}+q_{L}^{2}\right)}{q_{H}\left(q_{H}-q_{L}\right)\left(8 q_{H}-3 q_{L}\right)}$, with $\widetilde{b}>b_{\min }^{E}$. It follows that $\gamma^{* E}>0$ always when $b>\widetilde{b}$, and when $b \in\left(b_{\min }^{E}, \widetilde{b}\right)$ if $e>e_{\min }^{\gamma E}$. Second: $\gamma^{* E}<\gamma_{\max }^{E}$ for $e<\frac{q_{L}\left\{\left(7 q_{H}-2 q_{L}\right)\left(q_{H}-q_{L}\right)^{2}\left[c-b\left(q_{H}-q_{L}\right)\right]+\left[c+b s\left(q_{H}-q_{L}\right)\right]\left(4 q_{H}-q_{L}\right) q_{L}\right\}}{4 q_{H}^{3}\left(q_{H}-q_{L}\right)} \equiv e_{\max }^{\gamma E}$.

\section{Proof of Proposition 2}

The expression for the social welfare function when the government decides to levy a tax on the polluting firm is (12), where:

$$
\begin{aligned}
& C S_{L}^{* E}+C S_{H}^{* E}=\int_{\theta_{L}}^{\theta_{H}}\left(\theta q_{L}-p_{L}\right) d \theta+\int_{\theta_{H}}^{b}\left(\theta q_{H}-p_{H}\right) d \theta=\frac{q_{H}}{2\left(4 q_{H}-q_{L}\right)^{2}\left(q_{H}-q_{L}\right) q_{L}}\left\{t^{2} q_{H}\left(4 q_{H}-3 q_{L}\right)\right. \\
& \left.-2 t q_{L}\left(c q_{L}-4 b q_{H} q_{L}+4 b q_{H}^{2}\right)+q_{L}\left(6 b c q_{H} q_{L}+4 c^{2} q_{H}-3 c^{2} q_{L}-8 b c q_{H}^{2}+2 b c q_{L}^{2}+4 b^{2} q_{H}^{3}-5 b^{2} q_{H} q_{L}^{2}+b^{2} q_{H}^{2} q_{L}\right)\right\}
\end{aligned}
$$

Combining the results of Lemma 6 and Remark 3, by substituting into (12), we have:

$$
\begin{aligned}
\left.S W\right|_{t=0}= & \frac{1}{2\left(q_{L}-4 q_{H}\right)^{2}\left(q_{H}-q_{L}\right)}\left\{c^{2}\left(12 q_{H}^{2}-9 q_{H} q_{L}+2 q_{L}^{2}\right)-2 e q_{H}\left(q_{L}-4 q_{H}\right)\left(b q_{L}-b q_{H}-c\right)\right. \\
& \left.+b^{2} q_{H}\left(q_{L}-q_{H}\right)\left(q_{H} q_{L}-12 q_{H}^{2}+2 q_{L}^{2}\right)-2 b q_{H} c\left(5 q_{L}-12 q_{H}\right)\left(q_{L}-q_{H}\right)\right\},
\end{aligned}
$$




$$
\begin{gathered}
\left.S W\right|_{t=t^{* E}}=\frac{1}{2\left(q_{L}-q_{H}\right)\left(3 q_{L}-4 q_{H}\right) q_{L}}\left\{e^{2}\left(q_{L}-2 q_{H}\right)^{2}-2 e q_{L}\left(3 c q_{H}-2 c q_{L}-2 b q_{H} q_{L}+b q_{H}^{2}+b q_{L}^{2}\right)\right. \\
\left.+q_{L}\left[c^{2}\left(3 q_{H}-2 q_{L}\right)-2 b c\left(2 q_{L}-3 q_{H}\right)\left(q_{L}-q_{H}\right)+b^{2}\left(3 q_{H}^{3}+q_{L}^{3}-4 q_{H}^{2} q_{L}\right)\right]\right\} \\
\left.S W\right|_{t=t_{\max }^{E}}=\frac{\left(c-b q_{H}\right)^{2}\left(3 q_{H}-2 q_{L}\right)}{2\left(2 q_{H}-q_{L}\right)^{2}}
\end{gathered}
$$

When the campaign is adopted, social welfare as a function of $\gamma$ is given by (14), where:

$$
\begin{aligned}
C S_{L}^{* * E}+C S_{H}^{* * E}= & \frac{1}{2\left(4 q_{H}-q_{L}\right)^{2}\left(q_{H}-q_{L}\right) q_{L}}\left\{\gamma^{2}\left(q_{H} q_{L}+4 q_{H}^{2}-q_{L}^{2}\right)\left(q_{L}-q_{H}\right)^{2}\right. \\
& +q_{H} q_{L}\left(6 b c q_{H} q_{L}+4 c^{2} q_{H}-3 c^{2} q_{L}-8 b c q_{H}^{2}+2 b c q_{L}^{2}+4 b^{2} q_{H}^{3}-5 b^{2} q_{H} q_{L}^{2}+b^{2} q_{H}^{2} q_{L}\right) \\
& \left.-2 \gamma q_{H} q_{L}\left(q_{L}-q_{H}\right)\left[2 c\left(q_{L}-2 q_{H}\right)+b q_{L}\left(q_{H}-q_{L}\right)\right]\right\} .
\end{aligned}
$$

Lemma 8 and Remark 4 indicate that, by substituting into (14), we have:

$$
\left.S W\right|_{\gamma=0}=\left.S W\right|_{t=0} \text { by construction, }
$$

$$
\begin{aligned}
\left.S W\right|_{\gamma=\gamma^{* E}}= & \frac{1}{2\left(2 q_{L}^{4}-12 q_{H}^{4}+s q_{L}^{3}-15 q_{H} q_{L}^{3}-7 q_{H}^{3} q_{L}-8 s q_{H} q_{L}^{2}+16 s q_{H}^{2} q_{L}+32 q_{H}^{2} q_{L}^{2}\right)\left(q_{L}-q_{H}\right)}\{ \\
& 2 b q_{L} q_{H} c\left(q_{L}-q_{H}\right)\left(9 q_{H}^{3}-12 s q_{H} q_{L}+4 q_{L}^{3}+5 s q_{L}^{2}-9 q_{H} q_{L}^{2}-4 q_{H}^{2} q_{L}\right) \\
& -q_{L} c^{2}\left(2 s q_{L}^{3}-9 q_{H}^{4}+4 q_{H} q_{L}^{3}+22 q_{H}^{3} q_{L}-9 s q_{H} q_{L}^{2}+12 s q_{H}^{2} q_{L}-17 q_{H}^{2} q_{L}^{2}\right)+e^{2} 4 q_{H}^{4}\left(q_{L}-q_{H}\right) \\
& -q_{L} b^{2} q_{H}\left(q_{L}-q_{H}\right)\left(9 q_{H}^{4}+4 q_{L}^{4}+2 s q_{L}^{3}-5 q_{H} q_{L}^{3}+5 q_{H}^{3} q_{L}+s q_{H} q_{L}^{2}-12 s q_{H}^{2} q_{L}-13 q_{H}^{2} q_{L}^{2}\right) \\
-2 e\left[q_{L} q_{H} c\left(2 q_{L}^{3}-7 q_{H}^{3}-4 s q_{H} q_{L}+s q_{L}^{2}-11 q_{H} q_{L}^{2}+16 q_{H}^{2} q_{L}\right)\right] & \\
+ & \left.b\left(q_{H}-q_{L}\right)\left(7 q_{H}^{3}-4 s q_{H} q_{L}+2 q_{L}^{3}+s q_{L}^{2}-7 q_{H} q_{L}^{2}-2 q_{H}^{2} q_{L}\right)\right\} \\
\left.S W\right|_{\gamma=\gamma_{\max }^{E} \quad} & \frac{1}{8\left(q_{L}-q_{H}\right)^{2} q_{H}^{2}}\left\{2 b c\left(q_{L}-q_{H}\right)\left(3 q_{H}^{3}+2 q_{L}^{3}+s q_{L}^{2}-3 q_{H} q_{L}^{2}-2 q_{H}^{2} q_{L}\right)\right. \\
& +b^{2}\left(q_{L}-q_{H}\right)^{2}\left(2 q_{L}^{3}-3 q_{H}^{3}+s q_{L}^{2}+q_{H} q_{L}^{2}-4 q_{H}^{2} q_{L}\right) \\
& \left.-c^{2}\left(2 q_{L}^{3}-3 q_{H}^{3}+s q_{L}^{2}-7 q_{H} q_{L}^{2}+8 q_{H}^{2} q_{L}\right)\right\}
\end{aligned}
$$

We can now prove the main results which appear in Proposition 2. Consider only the case where we have internal solutions, i.e. we focus on the case where $s>s_{\min }$. By comparing the different $e$-thresholds one can find the four relevant cases. For each case, we perform the welfare comparisons. ${ }^{21}$

(i) When $b \in\left(b_{\min }^{E}, b_{1}\right)$, with $b_{\min }^{E}$ defined in $(1)$ and $b_{1}=\frac{2 c\left(28 q_{H}^{4}-53 q_{H}^{3} q_{L}+36 q_{H}^{2} q_{L}^{2}-10 q_{H} q_{L}^{3}+q_{L}^{4}\right)}{q_{H}\left(4 q_{H}-3 q_{L}\right)\left(q_{H}-q_{L}\right)\left(10 q_{H}^{2}-6 q_{H} q_{L}+q_{L}^{2}\right)}$, the ranking is as follows:

$$
e_{\min }^{t E}<e_{\max }^{t E}<e_{\min }^{\gamma E}<e_{\max }^{\gamma E} .
$$

For each subinterval we compare the relevant social welfare:

\footnotetext{
${ }^{21}$ We decided to omit the precise expressions for the welfare differences for the sake of brevity. They can be available upon request, as well as the analytical solutions and many numerical simulations which confirm our results.
} 
1. for $e \in\left(e_{\min }^{t E}, e_{\max }^{t E}\right),\left.S W\right|_{\gamma=0}-\left.S W\right|_{t=t^{* E}}<0$,

2. for $e \in\left(e_{\max }^{t E}, e_{\min }^{\gamma E}\right),\left.S W\right|_{\gamma=0}-\left.S W\right|_{t=t_{\max }^{E}}<0$,

3. for $e \in\left(e_{\min }^{\gamma E}, e_{\max }^{\gamma E}\right),\left.S W\right|_{\gamma=\gamma^{* E}}-\left.S W\right|_{t=t_{\max }^{E}}<0$,

4. for $e>e_{\max }^{\gamma E},\left.S W\right|_{\gamma=\gamma_{\max }^{E}}-\left.S W\right|_{t=t_{\max }^{E}}<0$.

We the confirm that for relatively low values of $b$ the taxation instrument is always preferred.

(ii) When $b \in\left(b_{1}, b_{2}\right)$, where $b_{2}=\frac{2 c\left(2 q_{H}-q_{L}\right)^{2}}{q_{H}\left(4 q_{H}^{2}-7 q_{H} q_{L}+3 q_{L}^{2}\right)}$, with $b_{2}>b_{1}$, we have two subcases:

$$
\begin{aligned}
& \text { (i) } e_{\min }^{t E}<e_{\min }^{\gamma E}<e_{\max }^{\gamma E}<e_{\max }^{t E} \text { when } s \in\left(s_{\min }, \widetilde{s}\right), \\
& \text { (ii) } e_{\min }^{t E}<e_{\min }^{\gamma E}<e_{\max }^{t E}<e_{\max }^{\gamma E} \text { when } s>\widetilde{s} .
\end{aligned}
$$

The first subcase is the most interesting, as we find that:

1. for $e \in\left(e_{\min }^{t E}, e_{\min }^{\gamma E}\right),\left.S W\right|_{\gamma=0}-\left.S W\right|_{t=t^{* E}}<0$;

2. for $e \in\left(e_{\min }^{\gamma E}, e_{\max }^{\gamma E}\right), S W_{\gamma=\gamma^{* E}}-\left.S W\right|_{t=t^{* E}}<0$ only when the quality ratio $q_{H} / q_{L}$ is not excessive. For very high values of $q_{H} / q_{L}$, there exists a threshold value of $e$ above which the environmental campaign is more efficient than the taxation instrument $\left(\left.S W\right|_{\gamma=\gamma^{* E}}-\right.$ $\left.\left.S W\right|_{t=t^{* E}}>0\right)$.

3. For $e \in\left(e_{\max }^{\gamma E}, e_{\max }^{t E}\right)$, we compare $\left.S W\right|_{\gamma=\gamma_{\max }^{E}} v s .\left.\quad S W\right|_{t=t^{* E}}$, and find that the environmental campaign is more efficient than the taxation instrument only for very high levels of $q_{H} / q_{L}$. As the environmental damage is more severe in this region, the result holds for each level of $e \in\left(e_{\max }^{\gamma E}, e_{\max }^{t E}\right)$. When the quality ratio is lower than a certain threshold value, then taxation prevails.

4. For $e>e_{\max }^{t E}$, we compare $\left.S W\right|_{\gamma=\gamma_{\max }^{E}}$ with $\left.S W\right|_{t=t_{\max }^{E}}$ and find similar results as in the previous interval.

In the second case $(s>\widetilde{s})$, on the contrary, the taxation instrument always prevails, as the cost for activating the campaign is now higher. We omit all the different subcases for brevity.

(iii) When $b \in\left(b_{2}, \widehat{b}\right)$, with $\widehat{b}=\frac{2 c\left(2 q_{H}-q_{L}\right)}{\left(q_{H}-q_{L}\right) q_{L}}$, we have three subcases:

$$
\begin{aligned}
& \text { (a) } e_{\min }^{\gamma E}<e_{\max }^{\gamma E}<e_{\min }^{t E}<e_{\max }^{t E} \text { when } s \in\left(s_{\min }, s_{1}\right), \\
& \text { (b) } e_{\min }^{\gamma E}<e_{\min }^{t E}<e_{\max }^{\gamma E}<e_{\max }^{t E} \text { when } s \in\left(s_{1}, \widetilde{s}\right) \\
& \text { (c) } e_{\min }^{\gamma E}<e_{\min }^{t E}<e_{\max }^{t E}<e_{\max }^{\gamma E} \text { when } s>\widetilde{s} .
\end{aligned}
$$

The first two subcases can be explained together, as they provide the same result. Notice in fact that the increase in parameter $b$ implied an important switch in the threshold values of $e$ as compared to the previous case. Consider for example subcase $(a)$, where the relevant welfare comparisons are: 
1. for $e \in\left(e_{\min }^{\gamma E}, e_{\max }^{\gamma E}\right),\left.S W\right|_{\gamma=\gamma^{* E}}>\left.S W\right|_{t=0}$, as can be immediately ascertained;

2. for $e \in\left(e_{\max }^{\gamma E}, e_{\min }^{t E}\right),\left.S W\right|_{\gamma=\gamma_{\max }^{E}}>\left.S W\right|_{t=0}$, and also this result is obvious;

3. for $e \in\left(e_{\min }^{t E}, e_{\max }^{t E}\right)$, we evaluate $\left.S W\right|_{\gamma=\gamma_{\max }^{E}}$ vis à vis $\left.S W\right|_{t=t^{* E}}$. Algebraic calculations confirm that $\left.S W\right|_{\gamma=\gamma_{\max }^{E}}>\left.S W\right|_{t=t^{* E}}$, and therefore the campaign is preferred.

4. Finally, for $e>e_{\max }^{t E}$, we find that $\left.S W\right|_{\gamma=\gamma_{\max }^{E}}>\left.S W\right|_{t=t_{\max }^{E}}$.

In subcase $(b)$, the only difference is that the taxation instrument can be adopted for a higher interval region of parameter $e$, given that $e_{\min }^{t E}<e_{\max }^{\gamma E}$. However, similar results as those for subcase (a) can be obtained, given that the cost for the campaign is still relatively low. Things change in subcase (c), where we allow for a substantial increase in such a cost. By analyzing the different subintervals of $e$, we find that:

1. for $e \in\left(e_{\min }^{\gamma E}, e_{\min }^{t E}\right),\left.S W\right|_{\gamma=\gamma^{* E}}>\left.S W\right|_{t=0}$, hence the (now costly) campaign still prevails when the environmental damage is perceived as limited.

2. for $e \in\left(e_{\min }^{t E}, e_{\max }^{t E}\right)$, we evaluate $\left.S W\right|_{\gamma=\gamma^{* E}}$ vS $\left.S W\right|_{t=t^{* E}}$. We find that the campaign is more efficient only when the quality ratio $q_{H} / q_{L}$ is sufficiently high and its cost is not too excessive; on the contrary, when $q_{H} / q_{L}$ decreases (meaning that the environmental quality of the brown good is not very different from that of the green good), there exists a threshold value of $e$ above which taxation is to be preferred, when $s$ is sufficiently high.

3. for $e \in\left(e_{\max }^{t E}, e_{\max }^{\gamma E}\right)$, we compare $\left.S W\right|_{\gamma=\gamma^{* E}}$ with $\left.S W\right|_{t=t_{\max }^{E}}$, and find the same results as in the previous subinterval.

4. Finally, for $e>e_{\max }^{\gamma E}$, we find that $\left.S W\right|_{\gamma=\gamma_{\max }^{E}}>\left.S W\right|_{t=t_{\max }^{E}}$ when the quality ratio is high and the cost of the campaign does not overcome a certain limit. Otherwise taxation is more efficient from the welfare standpoint.

(iii)bis When $b>\widehat{b}$, then $e_{\min }^{g E}<0$ and $e_{\min }^{t E}<0$. Therefore:

$$
\begin{aligned}
(a) \max \left\{0, e_{\max }^{\gamma E}\right\} & <e_{\max }^{t E} \text { when } s \in\left(s_{\min }, \widetilde{s}\right), \\
(b) e_{\max }^{t E} & <e_{\max }^{\gamma E} \text { when } s>\widetilde{s} .
\end{aligned}
$$

In the first subcase, the campaign is more efficient than the taxation instrument. We find that:

1. for $e \in\left(\max \left\{0, e_{\max }^{\gamma E}\right\}, e_{\max }^{\gamma E}\right)$, algebraic calculations show that $\left.S W\right|_{\gamma=\gamma_{\max }^{E}}>\left.S W\right|_{t=t^{* E}}$.

2. for $e>e_{\max }^{\gamma E},\left.S W\right|_{\gamma=\gamma_{\max }^{E}}>\left.S W\right|_{t=t_{\max }^{E}}$.

The result derives from the fact that the average evaluation of the environmental quality is relatively high, meaning that consumers attach a high value to the environmental performance of the product. Moreover, in this interval the cost to activate the campaign is relatively low.

In the second subcase, as one can easily guess after such a long exposition, we will find similar results as in the previous case, given that the cost for the campaign can be much higher than before. In fact, we find that: 
1. for $e \in\left(0, e_{\max }^{t E}\right)$, we compare $\left.S W\right|_{\gamma=\gamma^{* E}}$ with $\left.S W\right|_{t=t^{* E}}$ and discover that, as in the previous case (see subinterval 2), the campaign prevails when the quality ratio $q_{H} / q_{L}$ is sufficiently high and $s$ is not too high. When $q_{H} / q_{L}$ decreases, there exists a threshold value of $e$ above which taxation is to be preferred, provided the cost for the campaign $s$ is high enough.

2. For $e \in\left(e_{\max }^{t E}, e_{\max }^{\gamma E}\right)$, we compare $\left.S W\right|_{\gamma=\gamma^{* E}}$ with $\left.S W\right|_{t=t_{\max }^{E}}$; we find the same results as in the previous subinterval.

3. Finally, for $e>e_{\max }^{\gamma E}$, we evaluate $\left.S W\right|_{\gamma=\gamma_{\max }^{E}}$ vs. $\left.S W\right|_{t=t_{\max }^{E}}$ and replicate the results found in $e \in\left(0, e_{\max }^{\gamma E}\right)$ with the only difference that, when the quality ratio is very low and the cost of the campaign is sufficiently high, then taxation prevails for each value of $e>e_{\max }^{\gamma E}$.

\section{References}

[1] Akerlof, G. (1997), Social distance and social decisions", Econometrica, 65, pp.1005 -1027.

[2] Alexopoulos, M. and Sapp, S. (2006), Exploring the Behavior of Economic Agents: the role of relative preferences, Economics Bulletin, 12, pp.1 - 7.

[3] Ben Elhadj, N., Gabszewicz J., and O. Tarola (2013), Social awareness and duopoly competition, CORE DP 2013/43.

[4] Deltas, G., D. R. Harrington and M. Khanna, 2013, Oligopolies with (Somewhat) Environmentally Conscious Consumers: Market Equilibrium and Regulatory Intervention, Journal of Economics \& Management Strategy, 22: 640-667.

[5] Gabszewicz, J. and J.-F. Thisse (1979), Price Competition, Quality, and Income Disparities, Journal of Economic Theory, 20, pp. 340-359.

[6] Garcia-Gallego, A. and N. Georgantzis, 2009, Market effects of changes in consumers' social responsibility, Journal of Economics and Management Strategy, 18: 235-262.

[7] Ghazzai, H. (2008), Multi-product strategies and relative preferences for quality, Economics Bulletin, 34, pp. 1-10.

[8] Kahn, M. and M. J. Kotchen (2010), Environmental concern and the business cycle: the chilling effect of recession, NBER Working Paper 16241, http://www.nber.org/papers/w16241.

[9] Lambertini, L. (2013), Oligopoly, the Environment and Natural Resources: Incentives, Regulation and Sustainability. Routlegde.

[10] Leibenstein, H. (1950), Bandwagon, snob, and Veblen effects in the theory of consumer's demand, Quarterly Journal of Economics, 64, pp.183 - 207. 
[11] Lombardini-Riipinen, C. (2005), Optimal Tax Policy under Environmental Quality Competition, Environmental \& Resource Economics, 32, pp. 317-336.

[12] Mittnik, S., Semmler W., Kato M. and D. Samaan, (2013), Employment and Output Effects of Climate Policies, mimeo.

[13] Moraga-Gonzalez, J. L. and N. Padron-Fumero (2002), Environmental Policy in a Green Market, Environmental \& Resource Economics, 22, pp. 419-447.

[14] Sartzetakis, E. S., Xepapadeas A. and Petrakis, 2012, The role of information provision as a policy instrument to supplement environmental taxes, Environmental and Resource Economics, 52: 347-368.

[15] Shaked, A. and J. Sutton (1982), Relaxing Price Competition through Product Differentiation, Review of Economic Studies, 49, pp. 3-13.

[16] Special Eurobarometer 365 / WAVE EB 75.2 - TNS opinion and social. 


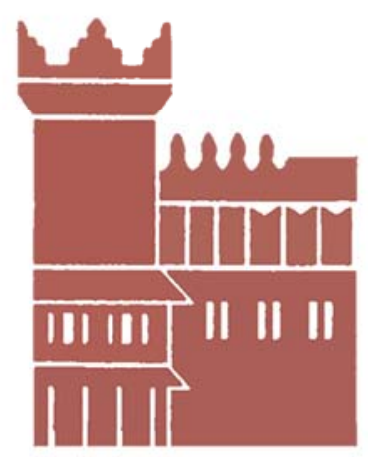

Alma Mater Studiorum - Università di Bologna DEPARTMENT OF ECONOMICS

Strada Maggiore 45

40125 Bologna - Italy

Tel. +39051 2092604

Fax +390512092664

http://www.dse.unibo.it 